OPEN ACCESS

Edited by:

Julia Kzhyshkowska,

Heidelberg University, Germany

Reviewed by:

Piergiuseppe De Berardinis, Consiglio Nazionale delle Ricerche

(Bologna), Italy

Paulo Bettencourt,

Catholic University of Portugal,

Portugal

*Correspondence:

Sanjay Phogat

sanjaykumar.x.phogat@gsk.com

Specialty section:

This article was submitted to

Vaccines and

Molecular Therapeutics,

a section of the journal

Frontiers in Immunology

Received: 05 May 2021

Accepted: 22 June 2021

Published: 07 July 2021

Citation:

Clegg J, Soldaini E, McLoughlin RM, Rittenhouse S, Bagnoli F and Phogat S (2021) Staphylococcus aureus Vaccine Research and Development: The Past, Present and Future, Including Novel Therapeutic Strategies.

Front. Immunol. 12:705360. doi: 10.3389/fimmu.2021.705360

\section{Staphylococcus aureus Vaccine Research and Development: The Past, Present and Future, Including Novel Therapeutic Strategies}

\author{
Jonah Clegg ${ }^{1,2}$, Elisabetta Soldaini ${ }^{1}$, Rachel M. McLoughlin ${ }^{2}$, Stephen Rittenhouse ${ }^{3}$, \\ Fabio Bagnoli ${ }^{1}$ and Sanjay Phogat ${ }^{1 *}$ \\ ${ }^{1}$ GSK, Siena, Italy, ${ }^{2}$ Host Pathogen Interactions Group, School of Biochemistry and Immunology, Trinity Biomedical \\ Sciences Institute, Trinity College Dublin, Dublin, Ireland, ${ }^{3}$ GSK, Collegeville, PA, United States
}

Staphylococcus aureus is one of the most important human pathogens worldwide. Its high antibiotic resistance profile reinforces the need for new interventions like vaccines in addition to new antibiotics. Vaccine development efforts against $S$. aureus have failed so far however, the findings from these human clinical and non-clinical studies provide potential insight for such failures. Currently, research is focusing on identifying novel vaccine formulations able to elicit potent humoral and cellular immune responses. Translational science studies are attempting to discover correlates of protection using animal models as well as in vitro and ex vivo models assessing efficacy of vaccine candidates. Several new vaccine candidates are being tested in human clinical trials in a variety of target populations. In addition to vaccines, bacteriophages, monoclonal antibodies, centyrins and new classes of antibiotics are being developed. Some of these have been tested in humans with encouraging results. The complexity of the diseases and the range of the target populations affected by this pathogen will require a multipronged approach using different interventions, which will be discussed in this review.

Keywords: Staphylococcus aureus, vaccinology, host-pathogen interactions, humoral immunity, models of infection

\section{INTRODUCTION}

Staphylococcus aureus is a gram-positive bacterium responsible for significant morbidity and mortality worldwide. In the United States of America, S. aureus is estimated to cause 20,000 deaths and amount to a total bill of $\$ 15$ billion on the health service annually $(1,2)$. S. aureus can be a highly lethal pathogen with a mortality rate during bacteremia of approximately $18 \%$ in developed countries $(1,3,4)$. This rate has been seen to increase in developing countries, establishing $S$. aureus as a global pathogen $(5,6)$. One of the most striking and challenging aspects of $S$. aureus clinical management is the ability of the bacterium to develop resistance to treatment with antibiotics. This effect was exemplified during the emergence of methicillin resistant $S$. aureus (MRSA) during the 1960 's and more recently with strains displaying moderate, and in very rare cases, complete 
resistance to vancomycin, one of the remaining treatment options for MRSA infection (7). Alternative therapies for $S$. aureus are therefore considered an urgent public need. Immunotherapies represent an attractive option due to the reduced likelihood for the development of resistance due to the multifaceted nature of the human immune system. The last two decades have seen considerable effort by the scientific community to develop a vaccine preventing $S$. aureus infection and yet, no vaccine candidates have proven successful at this objective during clinical testing.

$S$. aureus vaccine development has seen laudable innovation. Ever-increasing diversity in vaccine platforms is being observed as viewed through the wide array of antigen selection and the use of novel adjuvants and delivery systems aimed at harnessing specific humoral and cellular immunity. While data explaining the past failure of vaccines continues to emerge, it is imperative that this information is analyzed and reflected upon appropriately to maximize the likelihood of success when developing future vaccines. One of the most important factors that has held back the development of a vaccine is the lack of successful translation of vaccine protectivity that is observed in preclinical models of infection, to protective efficacy seen in human subjects. Here, we propose that the usage of more relevant animal models, more representative in vitro models and ex vivo human tissues to study the pathogenicity of $S$. aureus will increase the fidelity of data obtained at the preclinical level and therefore increase the likelihood of vaccines entering into clinical trials being efficacious. In addition to ongoing activities related to the development of a vaccine against $S$. aureus at the levels of vaccine design and preclinical testing, we discuss vaccines currently enrolled in clinical trials and alternative therapies for the treatment of $S$. aureus infection. We aim to provide this information while using evidence from past failings regarding $S$. aureus vaccine design, as well as lessons learned from non-S. aureus vaccine research, to provide a critical discussion of current research activities in order to pave the way for future research efforts in the field.

To further understand the challenges involved in creating an efficacious vaccine, we also give consideration to certain complexities of the host pathogen relationship between humans and $S$. aureus. Aside from being a major human pathogen with multiple virulence factors specifically focused on disarming key components of the immune system, S. aureus also establishes colonizing interactions which in turn results in most, if not all, individuals harboring pre-existing immunity $(8,9)$. A requirement for an efficacious vaccine will therefore be to improve upon natural immunity and so, provide protection from infection. In parallel to vaccine development, the emergence of novel therapeutic and short-term prophylactic treatments for $S$. aureus disease means that there are now numerous different strategies under investigation for the targeting of $S$. aureus (Figure 1). The revitalization of strategies such as bacteriophage therapy, monoclonal antibody treatment and antibiotics as well as the development of new therapeutic proteins such as centyrins, represent exciting experimental treatments for $S$. aureus.

\section{VACCINE DEVELOPMENT TECHNOLOGIES}

\section{Recombinant Proteins and Glycoconjugation}

The most common method employed during clinical trials of $S$. aureus vaccines has been the use of recombinant proteins or polysaccharide antigens of the bacterium to evoke a specific immune response in vaccine recipients. The choice of which antigen or combination of antigens to use is a question of paramount importance. Protein antigens typically considered for developing vaccines, are surface antigens or secreted toxins, for the following main reasons: 1) both can be detected by the immune response; 2) antibodies against surface antigens have the potential to induce opsonophagocytosis and block virulence functions (i.e., adhesion and nutrient uptake); 3) antibodies against secreted toxins can block toxicity. S. aureus possesses an extracellular polysaccharide coating which has been the target of multiple vaccine formulations entering into clinical trials. Following from the success of licensed vaccines against the bacterial pathogens: Streptococcus pneumoniae, Haemophilus influenzae $B$ and Neisseria meningitidis which used protein glycoconjugation in order to generate strong, long-lived, $\mathrm{T}$ celldependent $B$ cell immunity towards polysaccharide antigens, this strategy is also being applied to $S$. aureus vaccines (14). As opposed to the classical approach of chemical conjugation, bioconjugation is a more novel method of linking protein and polysaccharide antigens using genetically engineered bacteria to produce these conjugates (15). This technique was used to create an experimental vaccine for $S$. aureus in which the two most common capsular serotypes in clinical settings, CP5 and CP8 (16, 17), were conjugated to exoprotein A of Pseudomonas aeruginosa and importantly, a vaccine consisting of CP5 successfully conjugated to the $S$. aureus protein $\alpha$-toxin (Hla) was also generated (18). The conjugate containing two staphylococcal antigens proved to be the most immunogenic formulation in murine models of $S$. aureus bacteremia and pneumonia, therefore confirming two important principles for $S$. aureus vaccine development: 1) that "designer" glycoconjugates containing antigens from the same microbe are feasible and 2) that including carrier proteins from $S$. aureus increases vaccine immunogenicity. Considering that two of the most high-profile failures of prior S. aureus vaccines (Nabi's StaphVax and Pfizer's SA4Ag) used chemical conjugation to combine capsular polysaccharides to carrier proteins of unrelated bacteria, bioconjugation to native bacterial proteins may represent an area in which vaccine efficacy can be improved upon $(19,20)$. This point is further validated by the finding that an abundance of disease-causing $S$. aureus strains do not express a capsular polysaccharide (21).

\section{Extracellular Vesicles}

Gram-negative bacteria naturally secrete outer membrane vesicles (OMVs) composed of membrane-encapsulated periplasmic material. Being native secretions from bacteria, OMVs contain large amounts of pathogen associated molecular patterns 


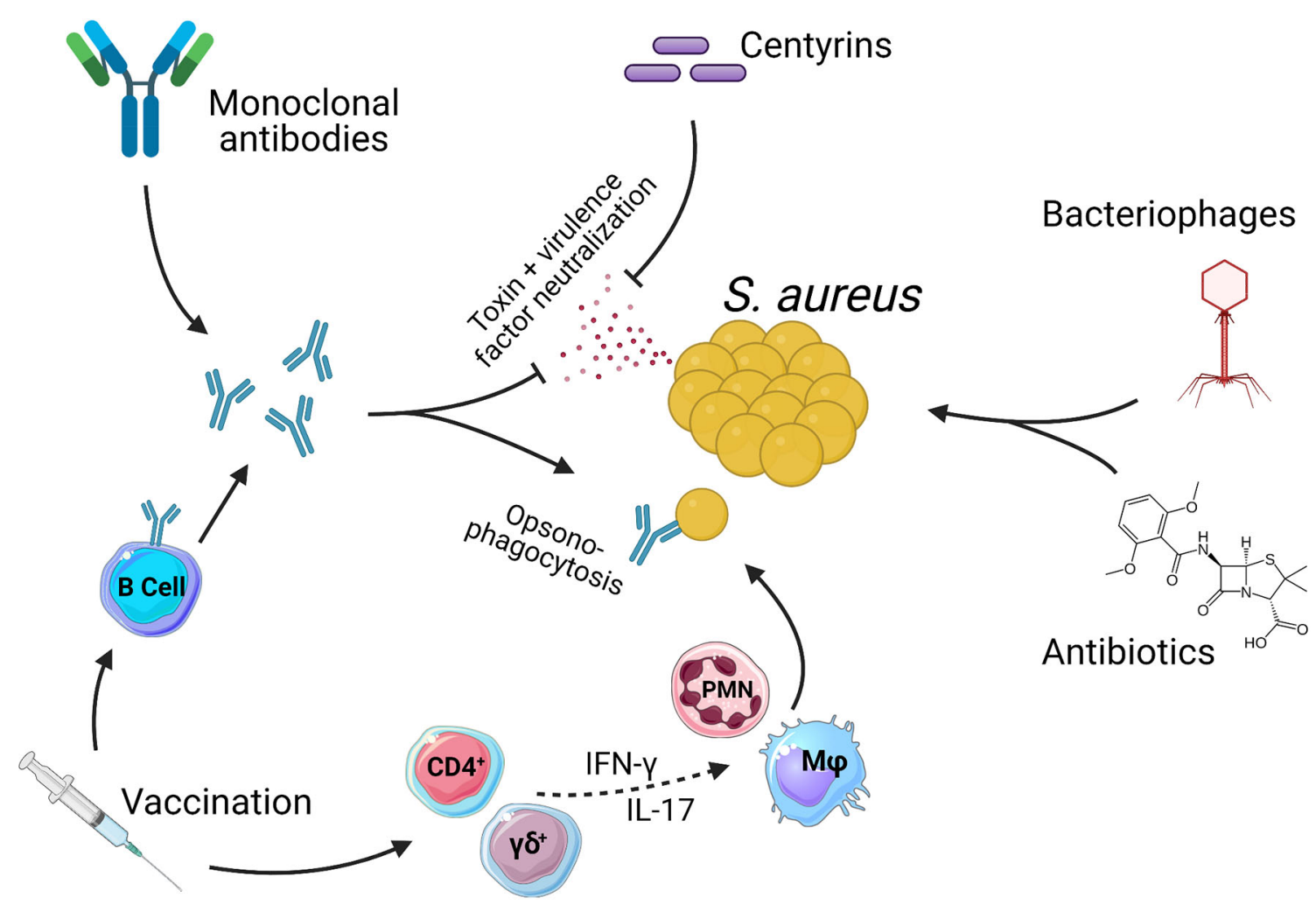

FIGURE 1 | Methods of targeting Staphylococcus aureus. There are numerous therapies being investigated as treatments for $S$. aureus infections. Antibiotics are currently the only option with clinical approval. Antibiotics act directly on bacteria via either bacteriostatic or bactericidal mechanisms. Bacteriophages also act directly on S. aureus to kill bacteria. Centyrins are small proteins with the ability to neutralize bacterial exo-toxins and virulence factors. Monoclonal antibodies can act in the same manner as centyrins to neutralize bacterial exo-toxins and virulence factors, with a secondary mechanism of opsonizing the bacteria due the presence of antibody Fc regions. Vaccines generate populations of memory B and T cells. B cells produce antibodies that act in the same manner as described for monoclonal antibodies. Memory T cells can also be induced which, through pro-inflammatory cytokines such as IFN- $\gamma$ and IL-17, aid in the activation and recruitment of innate effector cells such as Macrophage (M $\varphi$ ) and Neutrophils (PMN) which in turn kill bacteria. While $C D 4^{+} \mathrm{T}$ cells have a more classical role in adaptive memory responses, there is growing evidence to suggest that $\gamma \delta$ T cells may be induced by vaccination and play a protective role during $S$. aureus infections (10-13).

(PAMPs) such as bacterial lipopolysaccharide, which activate the innate immune system and display highly effective adjuvant properties $(22,23)$. Such inherent immunogenicity combined with a relative ease of production and the ability to incorporate non-native proteins has placed OMVs as an emerging and exciting vaccine delivery platform (24). This potential is being realized as we see vaccines using OMVs produced by genetically modified bacteria to increase antigenic yield and to reduce the toxic effects of endogenous Lipid A (known as Generalized Modules of Membrane Antigens or GMMAs) enter into clinical testing $(25,26)$. While $S$. aureus is a gram-positive bacterium, the applicability of OMV-based vaccination was recently demonstrated using Escherichia coli transfected with plasmids encoding five staphylococcal antigens, each fused to the leader sequence of the endogenous lipoprotein LPP, in order to traffic antigens into OMVs. Purified OMVs were used to successfully immunize mice against $S$. aureus sepsis, kidney abscess and skin infection (27). Interestingly, E. coli derived OMVs containing no staphylococcal antigens also provided strong protection against $S$. aureus sepsis and kidney abscess models. Such a finding may be a result of the short time frame between final immunization and infection (10 - 14 days) whereby residual immune potentiators induced through OMV immunization mediate antistaphylococcal defense or, suggest that OMVs themselves induce non-specific protective immunity, an effect known as innate immune memory or trained immunity that has previously shown to play a protective role during murine models of $S$. aureus infection (28-31).

As an alternative to using OMVs which are by definition derived from gram-negative bacteria, the discovery that gram-positive bacteria, including $S$. aureus, secrete extracellular vesicles (EVs) has led to their experimental use as a novel vaccination platform $(32,33)$. Proteomic analysis has revealed the composition of such EVs to be large and functionally heterogenous with cytoplasmic, secreted and cell membrane proteins with roles in cellular homeostasis, immune evasion and antibiotic resistance $(32,34)$. Similar to OMVs, S. aureus EVs display inherent adjuvant qualities, shown to drive the production of innate proinflammatory cytokines such as TNF- $\alpha$, IL- 6 and IL-12 in dendritic cells and dermal fibroblasts $(35,36)$. As such, EVs are expected to be highly 
capable of acting as standalone vaccine platforms. Indeed, during murine models of infection, mice immunized three times with $S$. aureus EVs demonstrated protective immunity towards subsequent $S$. aureus-induced pneumonia one week after receiving final vaccination and crucially, immunity was also demonstrated during a lethal model of $S$. aureus-induced sepsis 40 days after final vaccination, confirming the induction of long-term protective immunity (35). Interestingly, this immunity could be largely transferred via $\mathrm{T}$ cells and was completely abrogated upon the genetic deletion of IFN- $\gamma$. This finding echoes previous studies demonstrating $\mathrm{T}$ cell-derived IFN- $\gamma$ as a crucial mediator of protection during systemic $S$. aureus infections in humans and mice $(37,38)$. Interestingly, exosomes released by mammalian cells have recently been shown to exert a protective effect against $S$. aureus and other bacteria acting as decoys against Hla and other bacterial toxins (39).

\section{Whole Cell and Live-Attenuated S. aureus Vaccination}

Using chemically or physically inactivated or live-attenuated bacteria as a vaccine platform presents up and down-sides. Using whole cell bacteria ensures that a wide array of antigens are present to which a recipient may induce an immune response however, such vaccine formulations may also be associated with significant adverse events when compared to subunit vaccination, best exemplified in such vaccines against Bordetella pertussis (40). Furthermore, although live-attenuated vaccines possess an extremely low risk of mutating back into a virulent form, there are exceptions as is seen with the current vaccine-derived circulating strains of Poliovirus in Africa (41). Recently, an attenuated auxotrophic mutant of $S$. aureus MRSA strain 132 was created through genetic disruption of the Dalanine biosynthesis pathway, known to be essential for cell wall structure and viability across different bacterial phyla (42-45). While lethal at high doses $\left(1.1 \times 10^{9} \mathrm{CFU}\right)$, the auxotrophic strain of $S$. aureus was shown to be well tolerated by mice when introduced intraperitoneally at doses of $7 \times 10^{7} \mathrm{CFU}$ and lower (46). Furthermore, whether introduced intravenously or intraperitoneally, the auxotrophic strain was cleared within two days of administration. Excitingly, vaccination with this strain proved to be highly immunogenic protecting mice from lethal infection with $S$. aureus and further generating cross-reactive antibodies against a variety of $S$. aureus strains.

Inactivated whole cell vaccines have seen success in preclinical studies using both mouse and bovine models of $S$. aureus infection (47-49). In fact, there are currently two whole cell S. aureus vaccines (Lysigin ${ }^{\circledR}$ and Startvac ${ }^{\circledR}$ ) approved for use in preventing and reducing the severity of bovine mastitis. Notably, a study investigating the protective capability of Startvac ${ }^{\circledR}$ demonstrated a strong inverse correlation $(r=-0.71)$ between vaccine-specific IgG2 responses directed towards a polysaccharide antigen (known as slime associated antigenic complex) and survival of $S$. aureus during an infectious challenge (50). Considering that here the antigen in question is structural and not a $S$. aureus toxin or immune evasion protein, it is possible to extrapolate that humoral immunity either opsonizing bacteria or reducing bacterial attachment is important for $S$. aureus clearance during bovine mastitis. Aside from acting as an alternate model of infection, an important value of veterinarian vaccines for $S$. aureus such as Lysigin ${ }^{\circledR}$ and Startvac ${ }^{\circledR}$ is the possibility to examine efficacy of diverse vaccine systems in settings where infections can occur naturally, thereby better mimicking the situation in humans. At this point however, data showcasing prevention of infection or indeed pronounced reductions in severity of disease are lacking (51). As such, meaningful translatability of protection to human subjects in these vaccine systems is not readily indicated. In humans there has been reported success for whole-cell vaccines during early phase clinical trials of i) SA75 containing chloroform inactivated S. aureus and ii) heat-killed (HK) S. aureus of strain ATCC 12598 (52). While published data for the SA75 trial is lacking, the phase one trial was reported a success and similarly, within the trial of HK-ATCC 12598, no safety concerns were raised by patients. Nonetheless, these vaccines were not further developed. As mentioned above, development of such vaccines presents several limitations for reaching today's quality standards and that is why vaccine manufactures usually prefer newer technologies. Furthermore, both whole cell and live-attenuated vaccines are difficult to characterize as a reproducible product.

\section{Nucleic Acid Vaccines}

Nucleic acid vaccines deliver antigens encoded either as DNA or messenger RNA to cells which then transcribe and/or translate vaccine antigens into proteins. While until very recently no nucleic acid vaccines had been approved for human use, extremely promising RNA-based vaccine candidates against severe acute respiratory syndrome coronavirus 2 (SARS-CoV-2) rapidly progressed through clinical testing and, as of the time of writing this review (June 2021), two have been approved for human use (53, 54). The rapid progress made by both vaccines using an RNA vaccine platform has brought a renewal of interest into this vaccine strategy. To our knowledge, RNA-based vaccination has not yet been directly investigated with $S$. aureus in humans. One reason for this may be that (although there is long-standing evidence demonstrating the cross-presentation of endogenously derived antigens to class II MHC molecules) endogenously derived antigen is typically associated with presentation on class I MHC molecules, therefore favoring the generation of anti-viral immune responses such as $\mathrm{CD}^{+} \mathrm{T}$ cells $(55,56)$. In line with this, when pulsed with mRNAs encoding the $S$. aureus antigens SpA, MecA and SitC, healthy human monocyte-derived dendritic cells appeared to stimulate antigen-specific cytokine production in donor-matched $\mathrm{CD}^{+} \mathrm{T}$ cells to a greater degree than that of $\mathrm{CD}^{+} \mathrm{T}$ cells (57). Considering that intracellular survival of $S$. aureus in various cell types has been widely reported, $\mathrm{CD}^{+} \mathrm{T}$ cells may represent an understudied component of protective immunity during infection (58-60). mRNA based vaccination against group A and group B Streptococci has been shown to drive protective immune responses in mice, even providing transgenerational, humoral protection (61). As such, mRNA vaccination may well prove a viable strategy for immunization against gram-positive bacteria such as $S$. aureus. Another point of interest in this study from Maruggi and colleagues, 
was that the inclusion of a leader sequence targeting the group B Streptococcus protein BP-2a for cell secretion increased vaccine immunogenicity. Specifically, this relocalization of BP-2a led to greater survival rates amongst the pups of immunized mice when challenged with a lethal infection of Streptococcus agalactiae, an effect that was most apparent when a combined vaccine regime using priming RNA doses and a booster dose with recombinant protein was employed (61).

DNA vaccines consisting of plasmid encoded antigens are another intensely studied nucleic acid-based vaccine platform that has previously shown efficacy against $S$. aureus in preclinical studies during murine models of infection $(62,63)$. Like RNAbased vaccination, DNA vaccines carry with them the ability to prime $\mathrm{CD}^{+} \mathrm{T}$ Cells responses (62). However, a major obstacle that has obstructed the development of an efficacious DNAbased vaccine to date is the low immunogenicity observed in human subjects (64).

\section{Adjuvants}

Adjuvants are used to boost the immunogenicity of otherwise poorly immunogenic antigens. The majority of previously discussed vaccine platforms are considered self-adjuvanted due to the presence of PAMPs in the case of OMV-based and whole cell vaccines or due to the immunostimulatory nature of exogenously derived nucleic acids [though adjuvants have previously been shown to boost immunogenicity in nucleic acid vaccines (65)]. Recombinant proteins and glycoconjugates however, are more often combined with adjuvants as they do not contain any outright activators of the innate immune system and are therefore generally less immunogenic. In previous clinical trials for S. aureus, recombinant proteins and glycoconjugates have been used both with and without adjuvants. Two separate vaccine candidates, V710 and StaphVAX, which both failed during phase 3 clinical efficacy testing were unadjuvanted. Merck's V710 vaccine contained Iron Surface Determinant B (IsdB) while Nabi's StaphVAX contained CP5/CP8 capsular polysaccharides conjugated to $P$. aeruginosa exoprotein A (19, 66-68). In the case of StaphVax, efficacy in reducing S. aureus bacteremia was evident at an estimated level of efficacy of 57\% 40 weeks post-vaccination, however, by 54 weeks, efficacy drastically dropped to $26 \%$ (19). Vaccination with V710 showed minimal efficacy in reducing the onset of surgical site infection with $S$. aureus and actually increased the rate of mortality in those developing post-operative $S$. aureus infections (69). Mechanistically, this increased mortality has been previously linked to low endogenous levels of IL-2 and IL-17 in patients prior to receiving the vaccine (66). More recently, a novel mechanism explaining such worse outcomes was put forward by Nishitani and colleagues whereby at sites of surgical infection with $S$. aureus, antibodies against IsdB were shown to be captured in reverse orientation by the cell surface protein SpA. Here, the exposed Fab region of such antibodies may bind their target protein, IsdB which in turn binds its ligand: HemoglobinHaptoglobin complexes (70). Finally, Hemoglobin-Haptoglobin complexes are recognized and internalized by macrophages through the expression of CD163 which, due to the aforementioned ability of $S$. aureus to survive intracellularly, facilitates a behavior known as the Trojan horse hypothesis, whereby dissemination of $S$. aureus throughout the body occurs via macrophage migration within the blood supply $(71,72)$.

One possible explanation for these failures may be the lack of an adjuvant employed in both vaccines. Evidence for this hypothesis comes primarily from preclinical studies using murine models and demonstrating enhanced immunogenicity in $S$. aureus vaccine formulations after the inclusion of an adjuvant or demonstrating differential immune profiles in mice vaccinated with identical antigens using altered adjuvant systems. In fact, antigen-specific antibody titers (73-76), antigen-specific $\mathrm{T}$ cell responses $(74,76)$ as well as bacterial clearance and survival during subsequent infection (73-77) were all shown to increase with the inclusion of an adjuvant or to be significantly altered when comparing the use of different adjuvants, confirming the important impact an adjuvant may have on $S$. aureus vaccine efficacy. It should be noted however, that a recent study investigating the efficacy of various antigen combinations in murine models of skin and systemic $S$. aureus infections found no demonstrable differences in efficacy between a variety of adjuvants (78). Considering that in this study, no unadjuvanted control groups were included, and further that skin-infection was essentially attenuated by all vaccine formulations, meaningful conclusions are difficult to draw.

Although human data supporting a role for adjuvants in $S$. aureus vaccination is sparse, a phase 1 clinical trial for a $S$. aureus vaccine containing recombinant Hla, clumping factor a (ClfA) and $\mathrm{CP} 5 / \mathrm{CP} 8$ conjugated to tetanus toxoid, the adjuvant system AS03 was investigated. AS03 is an oil-in-water emulsion shown in previous clinical trials to significantly increase the immunogenicity of influenza vaccination $(79,80)$. The nonadjuvanted vaccine induced a rapid and potent antibody response towards the vaccine antigens suggesting that the vaccine induced a memory response, which pre-existed prior to vaccination. This phenomenon can be explained by the fact that humans are virtually all exposed to $S$. aureus and indeed the presence of antibodies against its antigens in healthy subjects has been documented (81). The effect for AS03 in boosting the $S$. aureus vaccine immunogenicity appeared not statistically superior as compared to the non-adjuvanted vaccine (82). The reason behind this may rely on the effect of pre-existing immunity, which makes antibody titers increase even without an adjuvant. In those conditions, it is likely that the quality, more than the quantity, of the antibodies can be improved in the presence of a proper adjuvant. However, it is difficult to derive any conclusions from the available clinical data on this hypothesis. Continuing with this idea, these findings open the door for a broader discussion on exactly what type of adjuvant should be considered for $S$. aureus vaccines.

Aside from the aforementioned use of AS03, all other $S$. aureus vaccines trialed in humans have used aluminum-based adjuvants. While yet to be fully understood, the mechanism through which alum-based adjuvants enhance the immunogenicity of vaccines is believed to be through a combination of antigen retention at the site of injection and 
local activation of the NLRP3 inflammasome to promote innate cytokine secretion $(83,84)$. Alum has been shown to specifically polarize T cells towards Th2 and Tfh subsets, both associated with protection from extracellular parasites and the generation of humoral immunity (85-88). While the correlates of immunity to $S$. aureus infection are not definitively established, a role is appreciated for that of cellular immunity, specifically Th1 and Th17 mediated immunity, as evidenced by genetic, clinical and experimental data $(38,89-91)$. Importantly, these findings help to demarcate a second reason as to why adjuvant selection is important in $S$. aureus vaccine design and why alternatives to alum may be required: directionality of the induced immune response. Like AS03, MF59 is an oil-in-water emulsion that is used in licensed influenza vaccines (92). In a preclinical study investigating the immunogenicity of a multi-component $S$. aureus vaccine containing FhuD2, Csa1A, Hla, EsxA, and EsxB, a direct comparison was conducted between alum and MF59-adjuvanted vaccines (74). When given the MF59adjuvanted vaccine, mice developed moderately enhanced antigen-specific memory $\mathrm{T}$ cell responses, demonstrated by $\mathrm{CD} 4^{+} \mathrm{T}$ cell proliferation and cytokine production, one month post-vaccination compared to that of mice receiving the alumadjuvanted vaccine, however this effect was not apparent at the four month time-point. Furthermore, evidence of greater protection afforded by the vaccine including MF59 was not wholly apparent when compared to the alum vaccine group. As such, while hinting at greater induction of $\mathrm{T}$ cell responses, MF59 does not appear to present itself as a clearly more efficacious adjuvant than alum in generating protective $S$. aureus immunity in a murine model.

Using the same experimental vaccine, a separate study found that inclusion of a TLR7 activating small molecule immune potentiator adsorbed onto alum could significantly enhance protective immunity in vaccinated mice versus control mice receiving a vaccine adjuvanted with alum alone (75). $\mathrm{T}$ cell responses were also greatly increased when compared to the alum only group, with enhancement of antigen-specific production of IL-2, TNF- $\alpha$, IFN- $\gamma$ and a trend towards an increase of IL-17 observed. Notably, no increase in Th2 cytokines was observed, suggesting that the directionality of the induced immune response was specifically focused (75). Indeed, further analysis confirmed the induction of Th17 immunity as well as Th1 immunity, and further found that vaccine-induced protective immunity was highly dependent on both humoral and $\mathrm{CD}^{+} \mathrm{T}$ cell responses (76). These encouraging results suggest that adjuvants acting through TLR7 may prove useful for the development of $S$. aureus vaccines.

Another TLR-activating adjuvant is CpG, composed of unmethylated cytosine and guanine repeats. When used as an adjuvant, CpG has been shown previously to evoke Th1 humoral and cellular responses in both mice and humans $(93,94)$. This Th1 biasing effect was harnessed in two separate studies to successfully develop protective vaccination regimes in mice against localized and systemic infections with $S$. aureus $(37,95$, 96). It should be noted that, in addition to Th1 responses, CpGmediated induction of antigen-specific humoral and Th17 immunity was also observed and correlated with protection from infection $(95,96)$. As such, the activity of CpG through TLR9 may represent a promising pathway for the induction of humoral and polyfunctional $\mathrm{T}$ cell responses associated with protection from $S$. aureus infections.

To summarize, the diversity observed in preclinical testing relating to vaccination strategies and choice of adjuvant is highly encouraging. While current research aims to elucidate the correlates of protection to $S$. aureus infection and to clinically validate the selection of particular antigens, diversity will be key to ensuring success in $S$. aureus vaccine design.

\section{MODELS FOR THE STUDY OF S. AUREUS INFECTIONS}

The conversation of $S$. aureus vaccine development is framed by past failings of clinical trials that all showed exciting promise during preclinical development. As such, we can conclude that the translation of preclinical data into clinical results is not successfully occurring. It's clear that more accurate preclinical models to study $S$. aureus infections and the human immune response to such infections are needed to improve the predictability of laboratory-generated vaccines in protecting human subjects. In addition, determining the correlates of protection of $S$. aureus infections requires faithful recapitulation of human tissues and the human immune system. The most utilized model for studying S. aureus infections is the mouse. On one hand, the gene expression profiles of $S$. aureus extracted from natural cutaneous infections of human patients or from the kidneys of mice with experimentally induced systemic infections have been shown to be similar (97). However, the ability of mice, and in particular laboratory mice, being able to recapitulate the human immune response to infection has been under scrutiny in recent years (98, 99). While this is undoubtedly true in a generalized immunological sense, $S$. aureus-specific examples of this effect can also be observed through the reduced affinity of staphylococcal toxins for nonhuman homologs of toxin receptors. For example, the bicomponent toxins: Panton-Valentine leukocidin (PVL), LukAB, $\mathrm{HlgCB}$ and $\mathrm{HlgAB}$ all display reduced affinity towards murine homologs of each of their human receptors, meaning that virulence mediated by these proteins may be missed through the use of mice $(100,101)$. This effect has been demonstrated through the infection of immunodeficient mice re-constituted with human hematopoietic stem cells, thereby classified as humanized mice. Studies exposing humanized mice to a variety of $S$. aureus infections, including pneumonia, skin infection and intraperitoneal infection consistently showed increased susceptibility compared to wild-type or immunodeficient controls (102-104). In one such study, the efficacy of successful humanization as measured by the ratio of human to murine $\mathrm{CD} 45^{+}$cells was directly correlated with the size of skin abscesses in mice and skin lesions were significantly reduced in humanized mice when a PVL-deficient strain of $S$. aureus was used, an effect not observed in wild-type mice (102). These findings combine to suggest that $S$. aureus host-specificity is a crucial factor for the outcome of infection and that humanization 
of mice may be a highly useful tool to increase the translatability of preclinical vaccine data (105). Notably, rabbits, while still much less than that of humans, are more susceptible to the effect of many $S$. aureus toxins, therefore suggesting rabbits as a more relevant in vivo model (106). S. aureus vaccines and monoclonal antibodies have also occasionally been tested in non-human primates, generating highly relevant data $(107,108)$.

An additional caution to be noted when using mouse models for the study of $S$. aureus pathology is that specific pathogen free mice purchased from commercial vendors, as well as laboratory housed mice, may be naturally colonized with mouse-adapted $S$. aureus (109-111). Considering that pre-exposure to S. aureus in the contexts of colonization and infection alter the host immune response to subsequent infection, as reported in both mice and humans (112-114), the potentiality that experimental mice may or not be pre-colonized introduces a confounding factor into preclinical research. From an alternative standpoint, the evidence of host adaptation occurring in mice colonized with $S$. aureus may actually give value to the mouse model via two mechanisms. Firstly, the opportunity to study previously reported, naturally developing $S$. aureus infections in mice would mirror the process of human infection much more closely than experimentally induced infections (110). Secondly, though mouse-derived strains of $S$. aureus will be less clinically relevant than humanderived strains, host-adaptation may allow for more accurate comparative immunology approaches to be undertaken when studying the mouse immune response to $S$. aureus.

An interesting alternative animal model for studying $S$. aureus pathology that has been mobilized in recent years is the Zebrafish. The benefits of using this more distantly related organism include: i) the ability to study innate immune responses before the adaptive immune system has developed (this only occurs four weeks after fertilization), ii) a high degree of evolutionary divergence between human and Zebrafish immune systems allows us to specifically examine the functionality of highly conserved genomic material, thereby reducing the complexity of the system in question and iii) advanced microscopy techniques are applicable to this model due to its transparent appearance (115). Indeed, while utilized significantly less than the mouse model, some important basic research findings concerning the pathogenicity of $S$. aureus as well as inferences of protective immunity were made using the Zebrafish model $(116,117)$.

The development of in vitro models to study human immunology is crucial towards moving away from the biologically and ethically undesirable use of animal models. Two leading approaches for recapitulating the physiological environment of human organs are: organoids and organs on chips. Organoids are cell culture models containing heterogenous cell types and anatomical organization that mimic a particular organ (118). In the context of S. aureus, the skin, lungs and bones represent some of the most common biological niches of non-systemic infection in humans. Therefore, establishing systems that model these organs in vitro could be relevant for the investigation of host immunity during infection. Recently, a human skin organoid was developed from human pluripotent stem cells that displayed complex architecture, hair production and a transcriptome all faithfully recapitulating that of human facial skin (119). Further still, cultured skin could be xenografted and integrated into a mouse model, therefore adding a significant degree of humanization for in vivo analysis of a hypothetical S. aureus infection. Similarly, the development of lung and bone organoid cultures has become more refined in recent years (120-122). Drawbacks to using organoids in $S$. aureus vaccinology research include i) the complexity of natural human tissue and the difficulty in fully re-creating such complexity in vitro ii) the inability to address the contribution of a tissue's microbiome iii) the lack of potentially important cell types, for example tissue-resident lymphocyte populations which are abundantly present in many organs and finally iv) a lack of interaction with a systemic immune system when used in isolation $(123,124)$.

Organs-on-chips consist of micro-scale organs, derived either from cell culture methods akin to that of an organoid or alternatively from ex vivo samples of an organ, often connected to a microfluidics system which mimics that of a physiologically relevant vascular system (125). The applicability of this model in studying S. aureus infections was recently demonstrated by Kim and colleagues. In this study, a micro-biopsy of skin was taken from healthy human subjects, infected with $S$. aureus and then loaded into a chip containing two chambers: one for the skin explant and another for the addition of one drop of whole blood. Importantly, blood and skin were separated by columns selectively allowing for the autonomous migration of neutrophils in response to chemotactic signals secreted by the skin (126). As such, it may be possible to obtain minimally invasive micro-samples of skin and blood from humans enrolled in clinical trials receiving $S$. aureus vaccines to determine whether skin-derived and/or systemic immunity raised by a vaccine may contribute to physiologically relevant protection from S. aureus infection, using this model. A lung organ-on-chip was also recently developed and investigated for its ability to study S. aureus infections. Here Deinhardt-Emmer et al. (127) used three cell lines to establish an artificial alveolus consisting of endothelial, epithelial and macrophage cells that was then infected with both S. aureus and influenza virus (127). The alveolus-on-chip was connected to a fluidics system consisting of a peristaltic pump ensuring unidirectional flow and a reservoir of cell culture medium, mimicking a circulatory system.

A highly valuable model to study the infective behavior of S. aureus are human ex vivo samples. Ex vivo samples are derived directly from human subjects and consist of complex tissues influenced by a natural microbiome, containing diverse genetic makeups and fully relevant cell populations. When considering $S$. aureus infections, there are some human tissues/fluids highly relevant to the study of host-pathogen interactions, that are also accessible for ex vivo analysis. For example, the transcriptome of $S$. aureus cultured ex vivo within human blood is distinct from that of the bacterium cultured in tryptic soy broth in vitro, also found with $S$. aureus derived from human sputum in cystic fibrosis patients $(128,129)$. The skin is another tissue of great relevance and opportunity for the study of $S$. aureus infectivity 
[asreviewed recently (130)]. Skin can be accessed through the donation of surgical waste samples, micro-biopsies and may even be probed in-situ, as demonstrated recently through the development of microneedle patches designed to extract interstitial fluid as well as antigen-specific lymphocytes from human skin (131). The cytokine response to $S$. aureus infection as well as the toxicity of Hla and PVL have previously been investigated using skin explant models, generating physiologically valuable data and a launchpad for future ex vivo analysis $(132,133)$. Recently, the presence of $S$. aureus-specific tissueresident $\mathrm{CD}^{+} \mathrm{T}$ cells in the skin of healthy subjects has been shown using abdominal skin explants (134). The protective efficacy of this frontline adaptive immune response could be harnessed by future vaccination strategies (135).

In summary, prior rates of failure demand alternatives to standard mouse models when investigating the protective capacity of experimental $S$. aureus vaccines and to determine the correlates of immunity to infection. While alternate animal models such as the zebrafish can help to elucidate certain aspects of $S$. aureus behavior, the further development and use of humanized mouse models or novel in vitro models such as organoids, organs-on-chips and ex vivo tissue culture will be critical in increasing the clinical translatability of laboratory generated data.

\section{AN UPDATE REGARDING ONGOING AND RECENTLY CONCLUDED CLINICAL TRIALS FOR S. AUREUS VACCINES}

There have recently been some key developments in the landscape of $S$. aureus vaccine development (Table 1). The most noteworthy of these is the phase IIb failure of Pfizer's SA4Ag vaccine candidate. Composed of recombinant MntC, ClfA and both CP5 and CP8, each conjugated to a detoxified form of diphtheria toxin, this vaccine was tested in four phase I clinical trials $(20,139-141)$ before ultimately failing to reach designated protection endpoints in a subsequent efficacy trial (NCT02388165). In phase I trials, a single dose of vaccine was sufficient to elicit high titers of specific and functional antibody responses in recipients from age 18-80 shown to last for at least a year after vaccination. Functionality was determined through antibody-mediated opsonophagocytic killing of bacteria and through inhibition of ClfA-mediated binding to its ligand, fibrinogen. Although SA4Ag was therefore deemed to be highly immunogenic, it failed to cause any reduction in the incidence of $S$. aureus bloodstream infections, surgical site infections or all-cause mortality within periods of 90 and 180 days after recipients underwent spinal surgery (NCT02388165). SA4Ag's failure in conferring protection to patients carries with it some critical lessons to be understood for S. aureus vaccinology. Firstly, and most crucially, the high immunogenicity of SA4Ag, as determined from assays analyzing the sera of vaccinees, had no bearing on its efficacy. One reason for this may be that the assays employed in order to classify the vaccine as immunogenic were not sufficient to capture the components of the immune system associated with preventing $S$. aureus infection. This issue stems again from the lack of defined correlates of protection to S. aureus infection, making the term "immunogenic" when applied to such vaccines somewhat misleading. In the case of SA4Ag, vaccineinduced humoral immunity was shown to be antigen specific in nature and capable of inducing bacterial opsonophagocytosis. Opsonophagocytic humoral responses were also demonstrated in both V710 and StaphVax vaccines that similarly failed efficacy testing in late-stage clinical trials $(19,69)$. As such, there is a growing consensus that using opsonophagocytosis as a readout for anti-staphylococcal immunogenicity is not sufficient as a standalone predictor of vaccine efficacy (143). Aligned with this point, none of the vaccine candidates that entered into late stage efficacy trials, reported on vaccine-induced $\mathrm{T}$ cell responses in humans, a potentially crucial aspect of immunogenicity when considering immunity from S. aureus infections. It is also possible that the in vitro assays used for measuring opsonophagocytosis were not predictive of this effect in vivo. For example, opsonophagocytosis assays are often performed using neutrophil-like cell lines as opposed to primary human neutrophils $(20,69,138)$.

Another lesson from SA4Ag's failure is that while retrospective analysis of Nabi's StaphVax vaccine seemed to indicate that waning antibody titres might lead to a decreased efficacy overtime (19), here SA4Ag was specifically shown to induce lasting humoral responses for periods of time longer than

TABLE 1 | Staphylococcus aureus vaccines currently enrolled in clinical trials.

\begin{tabular}{|c|c|c|c|c|c|}
\hline Company & Vaccine & Phase & Clinical trial number & Study population & Literature \\
\hline Olymvax & rFSAV: Hla, SpA, SEB, IsdB, MntC + Alum & II: Ongoing & $\begin{array}{l}\text { CTR20181788, } \\
\text { NCT03966040 }\end{array}$ & & (138) \\
\hline Pfizer & SA4Ag: CP5-dptx, CP8-dptx, ClfA, MntC & Illb: Failure & NCT02388165 & Patients undergoing spinal surgery & \\
\hline
\end{tabular}


the efficacy study itself (141). Considering that SA4Ag was given as a single, unadjuvanted dose, it is conceivable that administration of the vaccine acted to simply boost preexisting $S$. aureus immune responses without significantly enhancing the quality and functionality of humoral or cellular immunity.

There are at least five $S$. aureus vaccines currently engaged in various stages of clinical trials (Table 1). Novadigm's NDV3-A vaccine consists of the N-terminal part of the Candida albicans cell-wall protein Als3p adjuvanted with alum. Although a fungal protein, this vaccine provides cross-protection against $S$. aureus during murine models of bacteremia and skin infection due to cross-kingdom antigen overlap $(38,136,144)$. Currently this vaccine is in a phase II trial aimed at preventing nasal colonization with $S$. aureus in military personnel, a population in which the frequency of $S$. aureus skin infections is high (NCT03455309). Encouragingly, this vaccine has been associated with strong cellular immune responses in preclinical testing and crucially, was show to elicit antigen-specific production of the T cell cytokines IFN- $\gamma$ and IL-17 in human recipients during a phase I trial $(38,137)$. Furthermore, aside from IgG antibody responses, NDV3 was also found to induce a potent $\operatorname{IgA}$ response. Typically, non-IgG antibodies are not examined during the study of $S$. aureus immunity, however bovine research has suggested an anti-staphylococcal role for IgA and considering that in humans, S. aureus most commonly occupies mucosal niches, determining whether such antibodies can suppress colonization represents an area worth further study (145). Suppressing colonization is a novel clinical endpoint to set for an $S$. aureus vaccine and indeed, a crucial step for disease eradication, while also representing a major risk factor for the development of staphylococcal bacteremia $(146,147)$. A prior phase I trial by GSK investigating the safety and immunogenicity of a four-component vaccine containing: CP5, CP8, Hla and ClfA was found to have no effect on rates of $S$. aureus carriage over two years (82). This vaccine induced strong IgG responses and weak cellular immune responses in recipients suggesting that, as concluded when discussing vaccine efficacy, prevention of colonization may require more than robust IgG responses alone.

Olymvax have developed a $S$. aureus vaccine named rFSAV currently in phase II trials (CTR20181788). This vaccine is composed of five recombinant $S$. aureus antigens: Hla, SEB, $\mathrm{MntC}$, IsdB and $\mathrm{SpA}$ and showed promising efficacy in preclinical murine experiments (138). In addition to promoting opsonophagocytosis, sera from mice immunized with rFSAV were also shown to neutralize the lytic activity of Hla and prevent a slight depletion of splenic B cells observed in mice, mediated by treatment with SpA $(138,148)$. Importantly, this vaccine represents an alternate aspect of "immunogenicity" against $S$. aureus: inhibition of $S$. aureus immune-evasion strategies. This can be understood through the inclusion of both Hla and SpA in the vaccine formulation. Hla engages in the lytic killing of many leukocyte cell types and further disrupts cellular tight-junctions, facilitating S. aureus invasiveness (149, 150). Moreover, Hla intoxication leads to platelet aggregates that are deposited in the liver causing microvascular dysfunction and thrombosis in infected mice (151). In addition, Hla was recently shown to prevent the expansion of T cells during primary murine $S$. aureus skin infection, implicating itself as an important immune-evasion toxin (152). SpA acts both as a B cell superantigen and to sequester antibodies by their Fc portion, therefore functioning to suppress the humoral immune response through two separate mechanisms $(153,154)$. Lastly, SEB is known to induce rapid expansion, activation and subsequent anergy in a large proportion of the host $\mathrm{T}$ cell compartment (155). Considering the previously discussed evidence that antiIsdB antibodies may in fact be pathological, combined with clinical serological data reporting a similar phenomenon, extremely close observation should be kept on individuals receiving this experimental vaccine to prevent vaccine-induced mortality during $S$. aureus infections as seen in the V710 trial $(66,156)$.

Integrated BioTherapeutics have developed a heptavalent $S$. aureus vaccine consisting of seven $S$. aureus toxoids: Hla, Panton-Valentine Leukocidin (PVL) F and S subunits, Leukocidin A/B, SEA, SEB and Toxic shock syndrome toxin 1 (157). Preclinical data has shown that this vaccine, named IBTV02, confers protection to both mice and rabbits against $S$. aureus skin infection, with protection being entirely mediated by vaccine-induced antibodies (142). Interestingly, vaccine efficacy (as measured through the development of infectioninduced skin lesions) was unaffected when mice were preexposed intradermally to a low dose of $S$. aureus prior to vaccination. As mentioned previously, humans are naturally exposed to $S$. aureus and harbor pre-existing immunity (81). Pre-exposing mice to $S$. aureus therefore represents an encouraging degree of humanization to the mouse model. After receiving significant funding grants from the National Institute of Allergy and Infectious Disease and CARB-X, IBTV02 is expected to enter early phase clinical trials soon. Integrated BioTherapeutics are also developing a vaccine aimed specifically at neutralizing systemic toxicity induced by SEB which may find use in preventing potential SEB-related biological warfare attacks. This vaccine, consisting of a mutated, non-MHC-II binding recombinant SEB protein successfully completed a phase I trial in 2016 (158). GSK are in the recruiting phase of a phase I trial for their SA-5Ag vaccine (NCT04420221). The target population in this trial is listed as 18-50 year-olds with a recurrent $S$. aureus skin infection, a novel population for $S$. aureus vaccine trials.

\section{NOVEL THERAPEUTIC STRATEGIES FOR THE TREATMENT OF S. AUREUS INFECTIONS}

In parallel with vaccinology research, the development of therapeutic interventions for $S$. aureus-mediated disease is an area of constant innovation. In recent years, the revamping of older, more established treatment options as well as the development of completely novel strategies has created exciting 
hope for new treatment options against S. aureus. Herein, we discuss some of the most innovative and promising therapeutic interventions for the treatment of $S$. aureus infections.

\section{Novel Antibiotic Strategies}

Mortality rates due to $S$. aureus bacteremia are significantly higher in cases of MRSA bacteremia when compared to methicillin susceptible $S$. aureus (MSSA)-mediated disease with one study reporting mortality rates of $49.8 \%$ and $22.2 \%$ respectively (159). Such a finding is believed to be a result of the lower efficacy of daptomycin and vancomycin, the two first-line recommended interventions for MRSA infection, in treating S. aureus when compared to $\beta$-lactam antibiotics which are used to treat MSSA (160). Improving on this efficacy is therefore a priority for MRSA treatment, a sentiment captured in a recent statement from the World Health Organization following the completion of two reports investigating the global development of antimicrobial drugs, in which they warn that a lack of development will risk our ability to contain the spread of multi-drug resistant bacteria (161, 162). In early clinical and preclinical studies, novel antibiotics and delivery systems improving the efficacy of established antibiotics are being investigated along with the usage of novel drug combinations. An example of such effects at work can be seen by the recent development of DSTA4637S, an antibody-antibiotic conjugate consisting of a monoclonal antibody targeting $S$. aureus wall teichoic acid, fused to a novel rifamycinclass antibiotic (163). Mechanistically, DSTA4637S works to promote opsonophagocytosis which, upon entry into the intracellular phagolysosome of human phagocytes, initiates the cleavage of the fused antibiotic, and subsequent bacterial inhibition (164). Crucially, and unlike currently administered antibiotics, this mechanism is capable of effectively killing intracellular $S$. aureus, thereby reducing the ability of metastatic infections to occur. DSTA4637S recently completed a phase 1 trial (165).

The potential power of combination antibiotic therapy was recently exemplified in a small study of 40 participants in which daptomycin treatment was combined with the $\beta$-lactam ceftaroline. This study showed that combination treatment significantly reduced mortality when compared to either daptomycin or vancomycin treatment alone in patients with MRSA bacteremia (166). Though the mechanism for such synergy is not yet understood, it has been proposed that $\beta$ lactam antibiotics may directly enhance the bactericidal capacity of the innate immune system, thereby acting as an adjunct to daptomycin treatment (167).

Within the last three years, an abundance of novel mechanisms aiming to enhance the delivery of antistaphylococcal medicines towards site-specific infections such as skin and soft-tissue infections, implant related osteomyelitis or pneumonia have been developed in preclinical settings. For example, following the discovery that mesenchymal stem cells display antibacterial (including anti-S. aureus) activity (168, 169), Yoshitani and colleagues developed a novel therapeutic treatment in rats, consisting of adipose-derived stem cells loaded with the fluoroquinolone antibiotic ciprofloxacin, administered as a local injection to rats with experimentally-induced implantrelated $S$. aureus infections. This strategy was shown to decrease bacterial loads at the site of infection while further showing to outperform standard antibiotic treatment in decreasing osteomyelitis and bacterial abscess formation (170). A relatively more simplistic idea was recently applied for the delivery of hydrogel scaffolds mediating bone repair during a murine model of experimentally induced bone-defects. Here, the hydrogel scaffold was co-delivered with live S. aureus in order to model an implant-related infection however, upon the inclusion of the enzyme lysostaphin which displays potent anti-S. aureus activity to the scaffold, bacterial presence within implants was negligible at one and six weeks post-introduction of the infected scaffold (171). Focusing on a separate infection site, Hussain et al. (172) developed a $S$. aureus-binding peptide, using a combination of in vivo and in vitro phage display, and then coated silicon nanoparticles containing vancomycin with this peptide to target antibiotic delivery directly to live bacteria. Importantly, this strategy was shown to completely protect from $S$. aureus pneumonia-induced mortality during a murine model of infection (172). Positively charged silver nanoparticles are broad spectrum biocides that were used recently to functionalize catheter materials, leading to the effective inhibition of single- as well as dual-species $S$. aureus/C. albicans biofilm formation (173). Catheter-related bloodstream infections due to biofilm formation are a major healthcare problem and mixed bacterial/fungal biofilms formed by these two species represent a relevant clinical complication since $\beta-1$ 3 -glucan secreted by $C$. albicans provides $S$. aureus with enhanced antibiotic tolerance (174). In summary, an abundance of novel mechanisms involved in pharmacologically increasing the efficacy of antibiotics and in targeting antibiotics directly towards sites of infection are being developed, holding promise for the generation of novel therapeutics to treat S. aureus.

\section{Bacteriophage Therapy: Phages and Endolysins}

While not a novel strategy for the treatment of bacterial infections, bacteriophage therapies have seen a revitalization in recent years with numerous promising treatments in development for $S$. aureus infections as well as other notable antibiotic resistant bacteria in both preclinical and clinical stages $(161,175)$. Two distinct methods by which anti-staphylococcal viruses can be harnessed are through a) the use of virus-derived antibacterial enzymes such as endolysins and b) the injection of full viral particles. An example of a promising phage endolysin is SAL-200, developed by Intron Biotechnology. This S. aureusspecific enzyme demonstrated bactericidal activity against over 400 strains of $S$. aureus and was further shown to ameliorate outcomes to murine bacteremia while also synergizing with antibiotic treatment during murine and moth larval systemic infections to deliver greater therapeutic efficacy $(176,177)$. SAL200 has since entered into human clinical trials where it was firstly shown to be well tolerated in healthy volunteers and as such, has now entered into phase II testing (178) (NCT03089697, 
NCT03446053). Earlier this year CF-301, another bacteriophage endolysin, completed a proof-of-concept efficacy trial for the treatment of $S$. aureus bacteremia and endocarditis given as an adjunctive therapy with standard of care antibiotic treatment. Interestingly, though the additive efficacy of endolysin treatment during all S. aureus infections was $10 \%$ fourteen days posttreatment, restricting analysis to cases of MRSA demonstrated that over $42 \%$ of patients responded positively to adjunctive treatment (179). Such a finding is believed to reflect the previously discussed inferiority in anti-bacterial activity associated with antibiotics used during MRSA infections when compared to those used in MSSA infections. The activity of bacteriophage therapy has also been investigated for the treatment of more localized S. aureus infections. For example, a phase I trial was recently completed using the AB-SA01 bacteriophage cocktail demonstrating safety and preliminary indications of efficacy in combatting $S$. aureus mediated chronic rhinosinusitis (180). Consisting of three separate phages, this treatment has also recently been utilized in a small cohort of patients with severe systemic $S$. aureus infections lacking any non-treated controls (181). While the discussed data is promising, much remains to be seen concerning the use of bacteriophage therapies for $S$. aureus infections, paramount of which is large-scale efficacy. Some further outstanding issues that remain to be consolidated for bacteriophage therapy include: i) whether pre-existing or treatment-generated antibody responses will inhibit therapeutic efficacy and ii) whether bacteriophages or endolysins will be capable of killing intracellular S. aureus (182).

\section{Monoclonal Antibodies}

Passive immunization with monoclonal antibodies is an area of keen interest in the development of $S$. aureus therapeutics. Initially, efficacy trials of both poly and monoclonal antibodies targeting surface antigens of $S$. aureus such as: fibrinogen binding proteins (ClfA and Ser-Asp dipeptide repeat G), lipoteichoic acid and capsular polysaccharides showed largely disappointing results (183-185). More recently however, development has shifted towards monoclonal antibodies targeting staphylococcal toxins and immune evasion proteins as observed by the current antibody therapies engaged in clinical testing (Table 2). The furthest therapeutic along this track is the anti-Hla monoclonal antibody Tosatoxumab developed by Aridis, currently recruiting for a phase 3 trial in patients with $S$. aureus ventilator associated pneumonia (VAP) in addition to standard of care treatment (NCT03816956). Tosatoxumab completed a phase $1 / 2$ a trial on patients presenting with $S$. aureus pneumonia (including hospital acquired and community acquired pneumonia) showing to be well tolerated in recipients of the antibody. Furthermore, though statistical analysis was restricted to just 25 patients, when specifically looking at patients suffering from VAP, Tosatoxumab was found to significantly reduce the duration of time spent on emergency mechanical ventilation, therefore showing indications of efficacy in reducing $S$. aureusmediated disease (188). As such, larger scale data in this patient cohort is expected to reveal a clearer picture as to whether neutralization of alpha-toxin is indeed associated with effective treatment of $S$. aureus VAP. Another monoclonal antibody neutralizing the lytic activity of Hla, Suvratoxumab developed by AstraZeneca, has been developed to have an extended half-life within human blood and again has shown to be well tolerated within recipients $(191,192)$. Results of a phase II trial indicate that in patients receiving mechanical ventilation that are precolonized with S. aureus, Suvratoxumab displays some efficacy in reducing the development of $S$. aureus VAP, however the magnitude of efficacy at $31.9 \%$ was not sufficient to meet the efficacy endpoint of the study and furthermore did not reach statistical significance (189). In summation, though some encouraging results have been observed in the neutralization of Hla as both a prophylactic and therapeutic intervention in $S$. aureus VAP, further studies, particularly with larger sample sizes, are needed to provide a clear result demonstrating efficacy or a lack thereof.

Arsanis developed ASN-100, an antibody treatment consisting of two combined monoclonal antibodies that together target six lytic secreted toxins of $S$. aureus: Hla, PVL, gamma-hemolysin (HlgAB and HlgCB), LukED and LukGH $(193,194)$. ASN-100 was shown to protect rabbits during an experimental model of pneumonia to a much greater extent than protection offered by a Hla-neutralizing antibody alone (195). However, phase two

TABLE 2 | Therapeutic treatments for Staphylococcus aureus infections currently enrolled in clinical trials.

\begin{tabular}{|c|c|c|c|c|}
\hline Company & Medicine & Phase & $\begin{array}{l}\text { Clinical trial } \\
\text { number }\end{array}$ & Literature \\
\hline $\begin{array}{l}\text { Cumberland } \\
\text { Pharmaceuticals }\end{array}$ & Televancin: Vancomycin derivative & III failure & NCT02208063 & $(186)$ \\
\hline Arsanis & $\begin{array}{l}\text { ASN-100: Two monoclonal antibodies against Hla, PVL, gamma-hemolysin (HIgAB and } \\
\text { HlgCB), LukED and LukGH }\end{array}$ & II Failure & NCT02940626 & $(187)$ \\
\hline Genentech & DSTA4637S: Monoclonal antibody-antibiotic fusion targeting wall-teichoic acid & 1 & NCT02596399 & $(165)$ \\
\hline iNtRON Biotechnology & SAL200: Bacteriophage endolysin & \|l Ongoing & NCT03089697 & $(178)$ \\
\hline ContraFect & CF-301: Bacteriophage endolysin & II Completed & NCT03163556 & $(179)$ \\
\hline Aridis & Tosatoxumab: Monoclonal antibody against Hla & III Recruiting & NCT03816956 & $(188)$ \\
\hline AstraZeneca & Suvratoxumab: Monoclonal antibody against Hla & \| Completed & NCT02296320 & (189) \\
\hline X-Biotech & 514G3: Monoclonal antibody against SpA & || Completed & NCT02357966 & $(190)$ \\
\hline
\end{tabular}


clinical testing focusing on preventing the development of $S$. aureus VAP was halted before completion as it was deemed highly unlikely to meet its efficacy endpoints (NCT02940626).

Lastly, X-Biotech has developed 514G3, a monoclonal antibody against $\mathrm{SpA}$, that unlike previously mentioned monoclonal antibody platforms, is focused on treating $S$. aureus bacteremia. In order to counteract SpA's ability to sequester antibodies in their reverse orientation, 514G3 is an IgG3 isotype antibody, the sole subclass of IgG antibodies shown not to be bound in such a manner by SpA (196). Preclinical experiments demonstrated the efficacy of $514 \mathrm{G} 3$ in reducing $S$. aureus bacteremia-induced death in mice, while also showing an additive protective effect when mice where treated with vancomycin (197). 514G3 completed a combined phase I/II clinical trial on bacteremic patients in 2017 (190). Efficacy results from this trial have been publicly discussed by $\mathrm{X}$ Biotech, who reported a reduction in $S$. aureus related adverse effects in the treated group vs a placebo group (11\% vs. 26\%) however, statistical significance was not reached. Similarly, a non-significant reduction was observed in the duration of hospital stay in bacteremic patients $(\mathrm{p}=0.092)$. Considering 36 patients received 514G3 and just 16 received placebo, it may be possible that significance could be achieved in a larger scale trial. It should also be noted that an investigation into whether or not treatment was associated with at least one death during the study was inconclusive, raising the possibility of safety concerns during future trials (https://investors.xbiotech.com/node/6796/pdf).

Overall, the use of monoclonal antibodies as therapeutic and short-term prophylactic treatments for S. aureus remains an area with indications of promise but requires further validation in larger controlled clinical studies. Interestingly, it has previously been hypothesized that treatment with monoclonal antibodies may result in an enhanced development of long-term immunity. It is proposed that antibody coating of pathogens or secreted antigens leads to the formation of immune complexes, which are readily phagocytosed by antigen presenting cells thereby driving the development of robust, protective anamnestic immune responses (198). This effect could be measured through posttreatment observation of patients looking specifically at $S$. aureus infection incidence.

\section{Further Experimental Treatments for S. aureus}

Lesser studied but nonetheless highly promising strategies for treating $S$. aureus infections include centyrins, a novel class of therapeutic proteins based on the consensus sequence of the 15 fibronectin type 3 domains of the human protein Tenascin C (199). Centyrins can be considered as mimetics of monoclonal antibodies due to the fact that specific regions of the protein are highly mutable and may be selected for the ability to bind specifically to antigens with high affinity (199). Some notable differences when compared to monoclonal antibodies are that firstly, at less than $10 \%$ the size of IgG1 antibodies, centyrins are much smaller than monoclonal antibodies (200). Secondly, centyrins exist as unglycosylated single-chain proteins that lack disulfide bonds and therefore can easily be produced in large quantities in E. coli. Thirdly, due to the absence of an antibody Fc region, centyrins will not bind to cellular Fc receptors, thereby restricting their functionality to neutralization, not being able to induce opsonophagocytosis. Centyrins may therefore prove refractory to the sequestering effect of SpA on antibodies. Chan and colleagues recently developed centyrins capable of neutralizing the lytic activity of five bicomponent $S$. aureus toxins against human neutrophils, and further protected mice given otherwise lethal doses of LukED (201). The authors addressed the fact that centyrins have a short half-life which can be extended within human blood by fusing centyrins with albumin. This modification has previously been shown to extend centyrin half-life to approximately 7.5 days in Macaques, and yet, this is still far behind that of anti-toxin monoclonal antibodies used in previous clinical trials (21 - 112 days) $(187,192,202)$.

The previously mentioned effect of trained immunity is an area that may prove interesting for the development of alternative short-term prophylactic strategies for individuals undergoing surgeries and therefore risking the acquisition of an infection. Such an idea is evidenced from older studies demonstrating the protective effect of prior C. albicans infection on a subsequent S. aureus infection (203), to more recent publications recapitulating the same effect via vaccination with fungal cell wall components (known inducers of trained immunity) (204). The power of this effect has been observed previously in children vaccinated with the Bacille Calmette-Guérin vaccine, another known inducer of trained immunity (205).

\section{CONCLUSION}

Making a vaccine that can prevent $S$. aureus infection has proven to be challenging. S. aureus is a commensal organism of the human nasal mucosae and the skin that has adapted an array of armaments specifically focused on subverting the human immune system. In spite of this, the scientific community has continued to innovate and develop diverse and complex vaccine designs in order to evoke various arms of the immune system and to tackle many $S$. aureus virulence mechanisms. The bottleneck to licensure is the demonstration of efficacy at the clinical level. To give vaccines entering into clinical trials the best likelihood of success, validation at the preclinical level must be achieved using models that can better recapitulate the human condition during infection. Vaccines currently in clinical trials are using more defined endpoints, enrolling specific populations at risk of infection, targeting virulence and immune-evasion factors of $S$. aureus and have been shown to generate both humoral and cellular facets of the immune system.

The development of therapeutic and short-term prophylactic treatments for $S$. aureus infections is moving at an encouragingly high speed. Though in many ways the discussed treatments can 
TABLE 3 | Future directions of Staphylococcus aureus vaccinology research.

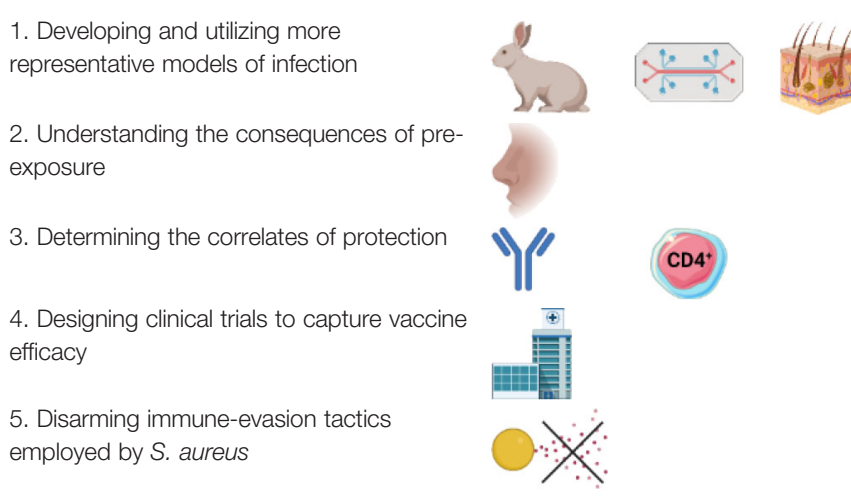

be imagined as alternatives for vaccination, instead of running parallel to each other, these seemingly distinct fields can generate highly transferrable information and collaborative opportunity. For example, if proven to be efficacious in treating an infection, short-term immunotherapies may outline and inform the antigenic targets of $S$. aureus vaccines. Furthermore, considering that clinical trials will use standard of care therapies as a baseline for the therapeutic efficacy, understanding how immunotherapies, antibiotics and vaccines may synergize could be highly important in future clinical trial

\section{REFERENCES}

1. Kourtis AP, Hatfield K, Baggs J, Mu Y, See I, Epson E, et al. Vital Signs: Epidemiology and Recent Trends in Methicillin-Resistant and in MethicillinSusceptible Staphylococcus aureus Bloodstream Infections - United States. MMWR Morb Mortal Wkly Rep (2019) 68:214-9. doi: 10.15585/ mmwr.mm6809e1

2. Suaya JA, Mera RM, Cassidy A, O'Hara P, Amrine-Madsen H, Burstin S, et al. Incidence and Cost of Hospitalizations Associated With Staphylococcus aureus Skin and Soft Tissue Infections in the United States From 2001 Through 2009. BMC Infect Dis (2014) 14. doi: 10.1186/1471-2334-14-296

3. Hill PC, Birch M, Chambers S, Drinkovic D, Ellis-Pegler RB, Everts R, et al. Prospective Study of 424 Cases of Staphylococcus aureus Bacteraemia: Determination of Factors Affecting Incidence and Mortality. Intern Med J (2001) 31:97-103. doi: 10.1046/j.1445-5994.2001.00029.x

4. Coombs GW, Daley DA, Lee YT, Pang S. Australian Group on Antimicrobial Resistance (AGAR) Australian Staphylococcus aureus Sepsis Outcome Programme (ASSOP) Annual Report 2017. Commun Dis Intell (2019) 43. doi: $10.33321 /$ cdi.2019.43.43

5. Eshwara VK, Munim F, Tellapragada C, Kamath A, Varma M, Lewis LE, et al. Staphylococcus aureus Bacteremia in an Indian Tertiary Care Hospital: Observational Study on Clinical Epidemiology, Resistance Characteristics, and Carriage of the Panton-Valentine Leukocidin Gene. Int J Infect Dis (2013) 17:e1051-5. doi: 10.1016/j.ijid.2013.06.002

6. Nickerson EK, Hongsuwan M, Limmathurotsakul D, Wuthiekanun V, Shah KR, Srisomang P, et al. Staphylococcus aureus Bacteraemia in a Tropical Setting: Patient Outcome and Impact of Antibiotic Resistance. PLoS One (2009) 4(1):e4308. doi: 10.1371/journal.pone.0004308

7. Park JW, Lee H, Kim JW, Kim B. Characterization of Infections With Vancomycin-Intermediate Staphylococcus aureus (VISA) and Staphylococcus aureus With Reduced Vancomycin Susceptibility in South Korea. Sci Rep (2019) 9(1):6236. doi: 10.1038/s41598-019-42307-6

8. Albrecht VS, Limbago BM, Moran GJ, Krishnadasan A, Gorwitz RJ, McDougal LK, et al. Staphylococcus aureus Colonization and Strain Type at Various Body Sites Among Patients With a Closed Abscess and Uninfected design. Our proposed future directions for S. aureus vaccinology research are listed in Table 3.

\section{AUTHOR CONTRIBUTIONS}

JC wrote the manuscript. JC, ES, SR, FB, RM, and SP revised and approved the manuscript. All authors contributed to the article and approved the submitted version.

\section{FUNDING}

This work was co-sponsored by GlaxoSmithKline Biologicals SA and associated research in Trinity College Dublin was supported by a Science Foundation Ireland Investigator Award (15/IA/ 3041) to RM. The funders was not involved in the study design, collection, analysis, interpretation of data, the writing of this article or the decision to submit it for publication.

\section{ACKNOWLEDGMENTS}

Figures were created with BioRender.com and Servier Medical Art.

Controls at U.S. Emergency Departments. J Clin Microbiol (2015) 53:3478-84 doi: 10.1128/JCM.01371-15

9. Dryla A, Prustomersky S, Gelbmann D, Hanner M, Bettinger E, Kocsis B, et al. Comparison of Antibody Repertoires Against Staphylococcus aureus in Healthy Individuals and in Acutely Infected Patients. Clin Diagn Lab Immunol (2005) 12:387-98. doi: 10.1128/CDLI.12.3.387-398.2005

10. Cho JS, Pietras EM, Garcia NC, Ramos RI, Farzam DM, Monroe HR, et al. IL-17 is Essential for Host Defense Against Cutaneous Staphylococcus aureus Infection in Mice. J Clin Invest (2010) 120:1762-73. doi: 10.1172/JCI40891

11. Marchitto MC, Dillen CA, Liu H, Miller RJ, Archer NK, Ortines RV, et al. Clonal V $\gamma 6+\mathrm{V} \delta 4+\mathrm{T}$ Cells Promote IL-17-Mediated Immunity Against Staphylococcus aureus Skin Infection. Proc Natl Acad Sci USA (2019) 166:10917-26. doi: 10.1073/pnas.1818256116

12. Dillen CA, Pinsker BL, Marusina AI, Merleev AA, Farber ON, Liu H, et al Clonally Expanded $\gamma \delta$ T Cells Protect Against Staphylococcus aureus Skin Reinfection. J Clin Invest (2018) 128:1026-42. doi: 10.1172/JCI96481

13. O'Brien EC, McLoughlin RM. Considering the 'Alternatives' for NextGeneration Anti-Staphylococcus aureus Vaccine Development. Trends Mol Med (2019) 25:171-84. doi: 10.1016/j.molmed.2018.12.010

14. Pollard AJ, Perrett KP, Beverley PC. Maintaining Protection Against Invasive Bacteria With Protein- Polysaccharide Conjugate Vaccines. Nat Rev Immunol (2009) 9:213-20. doi: 10.1038/nri2494

15. Ihssen J, Kowarik M, Dilettoso S, Tanner C, Wacker M, Thöny-Meyer L. Production of Glycoprotein Vaccines in Escherichia coli. Microb Cell Fact (2010) 9. doi: 10.1186/1475-2859-9-61

16. Mohamed N, Timofeyeva Y, Jamrozy D, Rojas E, Hao L, Silmon de Monerri NC, et al. Molecular Epidemiology and Expression of Capsular Polysaccharides in Staphylococcus aureus Clinical Isolates in the United States. PLoS One (2019) 14(1):e0208356. doi: 10.1371/JOURNAL.PONE.0208356

17. Verdier I, Durand G, Bes M, Taylor KL, Lina G, Vandenesch F, et al Identification of the Capsular Polysaccharides in Staphylococcus aureus Clinical Isolates by PCR and Agglutination Tests. J Clin Microbiol (2007) 45:725-9. doi: 10.1128/JCM.01572-06

18. Wacker M, Wang L, Kowarik M, Dowd M, Lipowsky G, Faridmoayer A, et al. Prevention of Staphylococcus aureus Infections by Glycoprotein 
Vaccines Synthesized in Escherichia Coli. J Infect Dis (2014) 209:1551-61. doi: 10.1093/infdis/jit800

19. Shinefield H, Black S, Fattom A, Horwith G, Rasgon S, Ordonez J, et al. Use of a Staphylococcus aureus Conjugate Vaccine in Patients Receiving Hemodialysis. $N$ Engl J Med (2002) 346:491-6. doi: 10.1056/nejmoa011297

20. Begier E, Seiden DJ, Patton M, Zito E, Severs J, Cooper D, et al. SA4Ag, a 4-Antigen Staphylococcus aureus Vaccine, Rapidly Induces High Levels of Bacteria-Killing Antibodies. Vaccine (2017) 35:1132-9. doi: 10.1016/ j.vaccine.2017.01.024

21. Boyle-Vavra S, Li X, Alam MT, Read TD, Sieth J, Cywes-Bentley C, et al. USA300 and USA500 Clonal Lineages of Staphylococcus aureus do Not Produce a Capsular Polysaccharide Due to Conserved Mutations in the Cap5 Locus. MBio (2015) 6(2):e02585-14. doi: 10.1128/mBio.02585-14

22. Bottero D, Gaillard ME, Zurita E, Moreno G, Martinez DS, Bartel E, et al. Characterization of the Immune Response Induced by Pertussis Omvs-Based Vaccine. Vaccine (2016) 34:3303-9. doi: 10.1016/j.vaccine.2016.04.079

23. Dowling DJ, Sanders H, Cheng WK, Joshi S, Brightman S, Bergelson I, et al. A Meningococcal Outer Membrane Vesicle Vaccine Incorporating Genetically Attenuated Endotoxin Dissociates Inflammation From Immunogenicity. Front Immunol (2016) 7:562. doi: 10.3389/fimmu.2016.00562

24. Kesty NC, Kuehn MJ. Incorporation of Heterologous Outer Membrane and Periplasmic Proteins Into Escherichia coli Outer Membrane Vesicles. J Biol Chem (2004) 279:2069-76. doi: 10.1074/jbc.M307628200

25. Launay O, Lewis DJM, Anemona A, Loulergue P, Leahy J, Sciré AS, et al. Safety Profile and Immunologic Responses of a Novel Vaccine Against Shigella Sonnei Administered Intramuscularly, Intradermally and Intranasally: Results From Two Parallel Randomized Phase 1 Clinical Studies in Healthy Adult Volunteers in Europe. EBioMedicine (2017) 22:164-72. doi: 10.1016/j.ebiom.2017.07.013

26. Gerke C, Colucci AM, Giannelli C, Sanzone S, Vitali CG, Sollai L, et al. Production of a Shigella Sonnei Vaccine Based on Generalized Modules for Membrane Antigens (GMMA), 1790GAHB. PLoS One (2015) 10. doi: 10.1371/journal.pone. 0134478

27. Irene C, Fantappiè L, Caproni E, Zerbini F, Anesi A, Tomasi M, et al. Bacterial Outer Membrane Vesicles Engineered With Lipidated Antigens as a Platform for Staphylococcus aureus Vaccine. Proc Natl Acad Sci USA (2019) 116:21780-8. doi: 10.1073/pnas.1905112116

28. Netea MG, Joosten LAB, Latz E, Mills KHG, Natoli G, Stunnenberg HG, et al. Trained Immunity: A Program of Innate Immune Memory in Health and Disease. Science (2016) 352:427. doi: 10.1126/science.aaf1098

29. Chan LC, Chaili S, Filler SG, Miller LS, Solis NV, Wang H, et al. Innate Immune Memory Contributes to Host Defense Against Recurrent Skin and Skin Structure Infections Caused by Methicillin-Resistant Staphylococcus aureus. Infect Immun (2017) 85(2):e00876-16. doi: 10.1128/IAI.00876-16

30. Chan LC, Rossetti M, Miller LS, Filler SG, Johnson CW, Lee HK, et al. Protective Immunity in Recurrent Staphylococcus aureus Infection Reflects Localized Immune Signatures and Macrophage-Conferred Memory. Proc Natl Acad Sci USA (2018) 115:E11111-9. doi: 10.1073/pnas.1808353115

31. Feuerstein R, Forde AJ, Lohrmann F, Kolter J, Ramirez NJ, Zimmermann J, et al. Resident Macrophages Acquire Innate Immune Memory in Staphylococcal Skin Infection. Elife (2020) 9:1-21. doi: 10.7554/eLife.55602

32. Lee EY, Choi DY, Kim DK, Kim JW, Park JO, Kim S, et al. Gram-Positive Bacteria Produce Membrane Vesicles: Proteomics-Based Characterization of Staphylococcus aureus-Derived Membrane Vesicles. Proteomics (2009) 9:5425-36. doi: 10.1002/pmic.200900338

33. Bose S, Aggarwal S, Singh DV, Acharya N. Extracellular Vesicles: An Emerging Platform in Gram-Positive Bacteria. Microb Cell (2021) 7:31222. doi: 10.15698/MIC2020.12.737

34. Wang X, Thompson CD, Weidenmaier C, Lee JC. Release of Staphylococcus aureus Extracellular Vesicles and Their Application as a Vaccine Platform. Nat Commun (2018) 9. doi: 10.1038/s41467-018-03847-z

35. Choi SJ, Kim MH, Jeon J, Kim OY, Choi Y, Seo J, et al. Active Immunization With Extracellular Vesicles Derived From Staphylococcus aureus Effectively Protects Against Staphylococcal Lung Infections, Mainly via Th1 CellMediated Immunity. PLoS One (2015) 10. doi: 10.1371/journal.pone.0136021

36. Hong SW, Kim MR, Lee EY, Kim JH, Kim YS, Jeon SG, et al. Extracellular Vesicles Derived From Staphylococcus aureus Induce Atopic DermatitisLike Skin Inflammation. Allergy Eur J Allergy Clin Immunol (2011) 66:351-9. doi: $10.1111 / j .1398-9995.2010 .02483 . x$
37. Brown AF, Murphy AG, Lalor SJ, Leech JM, O’Keeffe KM, Mac Aogáin M, et al. Memory Th1 Cells are Protective in Invasive Staphylococcus aureus Infection. PLoS Pathog (2015) 11. doi: 10.1371/journal.ppat.1005226

38. Lin L, Ibrahim AS, Xu X, Farber JM, Avanesian V, Baquir B, et al. Th1-Th17 Cells Mediate Protective Adaptive Immunity Against Staphylococcus aureus and Candida Albicans Infection in Mice. PLoS Pathog (2009) 5. doi: 10.1371/ journal.ppat.1000703

39. Keller MD, Ching KL, Liang FX, Dhabaria A, Tam K, Ueberheide BM, et al. Decoy Exosomes Provide Protection Against Bacterial Toxins. Nature (2020) 579:260-4. doi: 10.1038/s41586-020-2066-6

40. Patterson J, Kagina BM, Gold M, Hussey GD, Muloiwa R. Comparison of Adverse Events Following Immunisation With Acellular and Whole-Cell Pertussis Vaccines: A Systematic Review. Vaccine (2018) 36:6007-16. doi: 10.1016/j.vaccine.2018.08.022

41. Alleman MM, Jorba J, Greene SA, Diop OM, Iber J, Tallis G, et al. Update on Vaccine-Derived Poliovirus Outbreaks - Worldwide, July 2019-February 2020. MMWR Morb Mortal Wkly Rep (2020) 69:489-95. doi: 10.15585/ mmwr.mm6916al

42. Heaton MP, Johnston RB, Thompson TL. Controlled Lysis of Bacterial Cells Utilizing Mutants With Defective Synthesis of D-Alanine. Can J Microbiol (1988) 34:256-61. doi: 10.1139/m88-047

43. Palumbo E, Favier CF, Deghorain M, Cocconcelli PS, Grangette C, Mercenier A, et al. Knockout of the Alanine Racemase Gene in Lactobacillus Plantarum Results in Septation Defects and Cell Wall Perforation. FEMS Microbiol Lett (2004) 233:131-8. doi: 10.1016/j.femsle.2004.02.001

44. Wijsman HJW. The Characterization of an Alanine Racemase Mutant of Escherichia Coli. Genet Res (1972) 20:269-77. doi: 10.1017/\$001667230001380X

45. Steen A, Palumbo E, Deghorain M, Cocconcelli PS, Delcour J, Kuipers OP, et al. Autolysis of Lactococcus Lactis is Increased Upon D-Alanine Depletion of Peptidoglycan and Lipoteichoic Acids. J Bacteriol (2005) 187:114-24. doi: 10.1128/JB.187.1.114-124.2005

46. Moscoso M, García P, Cabral MP, Rumbo C, Bou G. A D-Alanine Auxotrophic Live Vaccine is Effective Against Lethal Infection Caused by Staphylococcus aureus. Virulence (2018) 9:604-20. doi: 10.1080/21505594 2017.1417723

47. Zhang F, Jun M, Ledue O, Herd M, Malley R, Lu YJ. Antibody-Mediated Protection Against Staphylococcus aureus Dermonecrosis and Sepsis by a Whole Cell Vaccine. Vaccine (2017) 35:3834-43. doi: 10.1016/j.vaccine. 2017.05.085

48. Tollersrud T, Zernichow L, Andersen SR, Kenny K, Lund A. Staphylococcus aureus Capsular Polysaccharide Type 5 Conjugate and Whole Cell Vaccines Stimulate Antibody Responses in Cattle. Vaccine (2001) 19:3896-903. doi: 10.1016/S0264-410X(01)00124-4

49. Burnside K, Lembo A, Harrell MI, Klein JA, Lopez-Guisa J, Siegesmund AM, et al. Vaccination With a UV-Irradiated Genetically Attenuated Mutant of Staphylococcus aureus Provides Protection Against Subsequent Systemic Infection. J Infect Dis (2012) 206:1734-44. doi: 10.1093/infdis/jis579

50. Prenafeta A, March R, Foix A, Casals I, Costa L. Study of the Humoral Immunological Response After Vaccination With a Staphylococcus aureus Biofilm-Embedded Bacterin in Dairy Cows: Possible Role of the Exopolysaccharide Specific Antibody Production in the Protection From Staphylococcus aureus Induced Mastitis. Vet Immunol Immunopathol (2010) 134:208-17. doi: 10.1016/j.vetimm.2009.09.020

51. Middleton JR, Ma J, Rinehart CL, Taylor VN, Luby CD, Steevens BJ. Efficacy of Different Lysigin ${ }^{\mathrm{TM}}$ Formulations in the Prevention of Staphylococcus aureus Intramammary Infection in Dairy Heifers. J Dairy Res (2006) 73:109. doi: $10.1017 / \mathrm{S} 0022029905001354$

52. Garcia-Romo GS, Gonzalez-Ibarra M, Donis-Hernandez FR, ZendejasBuitron VM, Pedroza-Gonzalez A. Immunization With Heat-Inactivated Staphylococcus aureus Induced an Antibody Response Mediated by Igg1 and Igg2 in Patients With Recurrent Tonsillitis. Microbiol Immunol (2015) 59:193-201. doi: 10.1111/1348-0421.12241

53. Mulligan MJ, Lyke KE, Kitchin N, Absalon J, Gurtman A, Lockhart S, et al. Phase I/II Study of COVID-19 RNA Vaccine BNT162b1 in Adults. Nature (2020) 586:589-93. doi: 10.1038/s41586-020-2639-4

54. Jackson LA, Anderson EJ, Rouphael NG, Roberts PC, Makhene M, Coler RN, et al. An mRNA Vaccine Against SARS-Cov-2 - Preliminary Report. N Engl J Med (2020) 383:1920-31. doi: 10.1056/nejmoa2022483 
55. Paludan C, Schmid D, Landthaler M, Vockerodt M, Kube D, Tuschl T, et al. Endogenous MHC Class II Processing of a Viral Nuclear Antigen After Autophagy. Science (2005) 307:593-6. doi: 10.1126/science.1104904

56. Jaraquemada D, Marti M, Long EO. An Endogenous Processing Pathway in Vaccinia Virus-Infected Cells for Presentation of Cytoplasmic Antigens to Class IIRestricted T Cells. J Exp Med (1990) 172:947-54. doi: 10.1084/jem.172.3.947

57. Uebele J, Stein C, Nguyen MT, Schneider A, Kleinert F, Tichá O, et al. Antigen Delivery to Dendritic Cells Shapes Human CD4+and CD8+T Cell Memory Responses to Staphylococcus aureus. PLoS Pathog (2017) 13. doi: 10.1371/journal.ppat.1006387

58. Zautner AE, Krause M, Stropahl G, Holtfreter S, Frickmann H, Maletzki C, et al. Intracellular Persisting Staphylococcus aureus is the Major Pathogen in Recurrent Tonsillitis. PLoS One (2010) 5. doi: 10.1371/journal.pone.0009452

59. Sachse F, Becker K, Von Eiff C, Metze D, Rudack C. Staphylococcus aureus Invades the Epithelium in Nasal Polyposis and Induces IL-6 in Nasal Epithelial Cells In Vitro. Allergy Eur J Allergy Clin Immunol (2010) 65:1430-7. doi: 10.1111/j.1398-9995.2010.02381.x

60. O’Keeffe KM, Wilk MM, Leech JM, Murphy AG, Laabei M, Monk IR, et al. Manipulation of Autophagy in Phagocytes Facilitates Staphylococcus aureus Bloodstream Infection. Infect Immun (2015) 83:3445-57. doi: 10.1128/ IAI.00358-15

61. Maruggi G, Chiarot E, Giovani C, Buccato S, Bonacci S, Frigimelica E, et al. Immunogenicity and Protective Efficacy Induced by Self-Amplifying mRNA Vaccines Encoding Bacterial Antigens. Vaccine (2017) 35:361-8. doi: 10.1016/j.vaccine.2016.11.040

62. Gaudreau MC, Lacasse P, Talbot BG. Protective Immune Responses to a Multi-Gene DNA Vaccine Against Staphylococcus aureus. Vaccine (2007) 25:814-24. doi: 10.1016/j.vaccine.2006.09.043

63. Senna JPM, Roth DM, Oliveira JS, Machado DC, Santos DS. Protective Immune Response Against Methicillin Resistant Staphylococcus aureus in a Murine Model Using a DNA Vaccine Approach. Vaccine (2003) 21:2661-6. doi: 10.1016/S0264-410X(02)00738-7

64. Hobernik D, Bros M. DNA Vaccines-How Far From Clinical Use? Int J Mol Sci (2018) 19. doi: 10.3390/ijms19113605

65. Brito LA, Chan M, Shaw CA, Hekele A, Carsillo T, Schaefer M, et al. A Cationic Nanoemulsion for the Delivery of Next-Generation RNA Vaccines. Mol Ther (2014) 22:2118-29. doi: 10.1038/mt.2014.133

66. McNeely TB, Shah NA, Fridman A, Joshi A, Hartzel JS, Keshari RS, et al. Mortality Among Recipients of the Merck V710 Staphylococcus aureus Vaccine After Postoperative s. Aureus Infections: An Analysis of Possible Contributing Host Factors. Hum Vaccines Immunother (2014) 10:3513-6. doi: $10.4161 / \mathrm{hv} .34407$

67. Fowler VG, Proctor RA. Where Does a Staphylococcus aureus Vaccine Stand? Clin Microbiol Infect (2014) 20:66-75. doi: 10.1111/1469-0691.12570

68. Fattom A, Fuller S, Propst M, Winston S, Muenz L, He D, et al. Safety and Immunogenicity of a Booster Dose of Staphylococcus aureus Types 5 and 8 Capsular Polysaccharide Conjugate Vaccine (Staphvax ${ }^{\circledR}$ ) in Hemodialysis Patients. Vaccine (2004) 23:656-63. doi: 10.1016/j.vaccine.2004.06.043

69. Fowler VG, Allen KB, Moreira ED, Moustafa M, Isgro F, Boucher HW, et al. Effect of an Investigational Vaccine for Preventing Staphylococcus aureus Infections After Cardiothoracic Surgery: A Randomized Trial. JAMA - J Am Med Assoc (2013) 309:1368-78. doi: 10.1001/jama.2013.3010

70. Torres VJ, Pishchany G, Humayun M, Schneewind O, Skaar EP. Staphylococcus aureus IsdB is a Hemoglobin Receptor Required for Heme Iron Utilization. J Bacteriol (2006) 188:8421-9. doi: 10.1128/JB.01335-06

71. Thwaites GE, Gant V. Are Bloodstream Leukocytes Trojan Horses for the Metastasis of Staphylococcus aureus? Nat Rev Microbiol (2011) 9:215-22. doi: $10.1038 /$ nrmicro2508

72. Nishitani K, Ishikawa M, Morita Y, Yokogawa N, Xie C, De Mesy Bentley KL, et al. IsdB Antibody-Mediated Sepsis Following S. aureus Surgical Site Infection. JCI Insight (2020) 5. doi: 10.1172/jci.insight.141164

73. Yang LY, Zhou H, Yang Y, Tong YN, Peng LS, Zhu BH, et al. Protective Effects of a Nanoemulsion Adjuvant Vaccine (2C-Staph/NE) Administered Intranasally Against Invasive Staphylococcus aureus Pneumonia. RSC $A d v$ (2018) 8:9996-10008. doi: 10.1039/c7ra13630g

74. Monaci E, Mancini F, Lofano G, Bacconi M, Tavarini S, Sammicheli C, et al. MF59- and $\mathrm{Al}(\mathrm{OH}) 3$-Adjuvanted Staphylococcus aureus (4C-Staph) Vaccines Induce Sustained Protective Humoral and Cellular Immune
Responses, With a Critical Role for Effector CD4 T Cells at Low Antibody Titers. Front Immunol (2015) 6:439. doi: 10.3389/fimmu.2015.00439

75. Bagnoli F, Fontana MR, Soldaini E, Mishra RPN, Fiaschi L, Cartocci E, et al. Vaccine Composition Formulated With a Novel TLR7-Dependent Adjuvant Induces High and Broad Protection Against Staphylococcus aureus. Proc Natl Acad Sci USA (2015) 112:3680-5. doi: 10.1073/pnas.1424924112

76. Mancini F, Monaci E, Lofano G, Torre A, Bacconi M, Tavarini S, et al. One Dose of Staphylococcus aureus 4C-Staph Vaccine Formulated With a Novel TLR7Dependent Adjuvant Rapidly Protects Mice Through Antibodies, Effector CD4+ T Cells, and IL-17A. PLoS One (2016) 11. doi: 10.1371/journal.pone.0147767

77. Sun HW, Wei C, Liu BS, Jing HM, Feng Q, Tong YN, et al. Induction of Systemic and Mucosal Immunity Against Methicillin-Resistant Staphylococcus aureus Infection by a Novel Nanoemulsion Adjuvant Vaccine. Int J Nanomed (2015) 10:7275-90. doi: 10.2147/IJN.S91529

78. Luna BM, Nielsen TB, Cheng B, Pantapalangkoor P, Yan J, Boyle-Vavra S, et al. Vaccines Targeting Staphylococcus aureus Skin and Bloodstream Infections Require Different Composition. PLoS One (2019) 14. doi: 10.1371/journal.pone.0217439

79. Garçon N, Vaughn DW, Didierlaurent AM. Development and Evaluation of AS03, an Adjuvant System Containing $\alpha$-Tocopherol and Squalene in an Oil-in-Water Emulsion. Expert Rev Vaccines (2012) 11:349-66. doi: 10.1586/erv.11.192

80. Leroux-Roels I, Borkowski A, Vanwolleghem T, Dramé M, Clement F, Hons E, et al. Antigen Sparing and Cross-Reactive Immunity With an Adjuvanted Rh5n1 Prototype Pandemic Influenza Vaccine: A Randomised Controlled Trial. Lancet (2007) 370:580-9. doi: 10.1016/S0140-6736(07)61297-5

81. Rigat F, Bartolini E, Dalsass M, Kumar N, Marchi S, Speziale P, et al. Retrospective Identification of a Broad Igg Repertoire Differentiating Patients With S. aureus Skin and Soft Tissue Infections From Controls. Front Immunol (2019) 10:114. doi: 10.3389/fimmu.2019.00114

82. Levy J, Licini L, Haelterman E, Moris P, Lestrate P, Damaso S, et al. Safety and Immunogenicity of an Investigational 4-Component Staphylococcus aureus Vaccine With or Without AS03B Adjuvant: Results of a Randomized Phase I Trial. Hum Vaccines Immunother (2015) 11:620-31. doi: 10.1080/ 21645515.2015.1011021

83. de Veer M, Kemp J, Chatelier J, Elhay MJ, Meeusen ENT. The Kinetics of Soluble and Particulate Antigen Trafficking in the Afferent Lymph, and its Modulation by Aluminum-Based Adjuvant. Vaccine (2010) 28:6597-602. doi: 10.1016/j.vaccine.2010.07.056

84. Li H, Willingham SB, Ting JP-Y, Re F. Cutting Edge: Inflammasome Activation by Alum and Alum's Adjuvant Effect are Mediated by NLRP3. J Immunol (2008) 181:17-21. doi: 10.4049/jimmunol.181.1.17

85. Comoy EE, Capron A, Thyphronitis G. In Vivo Induction of Type 1 and 2 Immune Responses Against Protein Antigens. Int Immunol (1997) 9:523-31. doi: 10.1093/intimm/9.4.523

86. Brewer JM, Conacher M, Hunter CA, Mohrs M, Brombacher F, Alexander J. Aluminium Hydroxide Adjuvant Initiates Strong Antigen-Specific Th2 Responses in the Absence of IL-4- or IL-13-Mediated Signaling. J Immunol (1999) 163:6448-54.

87. Serre K, Bénézech C, Desanti G, Bobat S, Toellner KM, Bird R, et al. Helios is Associated With CD4 T Cells Differentiating to T Helper 2 and Follicular Helper T Cells In Vivo Independently of Foxp3 Expression. PLoS One (2011) 6. doi: 10.1371/journal.pone.0020731

88. Anthony RM, Rutitzky LI, Urban JF, Stadecker MJ, Gause WC. Protective Immune Mechanisms in Helminth Infection. Nat Rev Immunol (2007) 7:975-87. doi: $10.1038 /$ nri2199

89. Crum-Cianflone NF, Burgi AA, Hale BR. Increasing Rates of CommunityAcquired Methicillin-Resistant Staphylococcus aureus Infections Among HIV-Infected Persons. Int J STD AIDS (2007) 18:521-6. doi: 10.1258/ 095646207781439702

90. Puel A, Cypowyj S, Bustamante J, Wright JF, Liu L, Lim HK, et al. Chronic Mucocutaneous Candidiasis in Humans With Inborn Errors of Interleukin17 Immunity. Science (2011) 332:65-8. doi: 10.1126/science.1200439

91. Minegishi Y, Saito M, Nagasawa M, Takada H, Hara T, Tsuchiya S, et al. Molecular Explanation for the Contradiction Between Systemic Th17 Defect and Localized Bacterial Infection in Hyper-Ige Syndrome. J Exp Med (2009) 206:1291-301. doi: 10.1084/jem.20082767

92. Essink B, Fierro C, Rosen J, Figueroa AL, Zhang B, Verhoeven C, et al. Immunogenicity and Safety of MF59-Adjuvanted Quadrivalent Influenza 
Vaccine Versus Standard and Alternate B Strain MF59-Adjuvanted Trivalent Influenza Vaccines in Older Adults. Vaccine (2020) 38:242-50. doi: 10.1016/j.vaccine.2019.10.021

93. Sugai T, Mori M, Nakazawa M, Ichino M, Naruto T, Kobayashi N, et al. A Cpg-Containing Oligodeoxynucleotide as an Efficient Adjuvant Counterbalancing the Th1/Th2 Immune Response in Diphtheria-TetanusPertussis Vaccine. Vaccine (2005) 23:5450-6. doi: 10.1016/ j.vaccine.2004.09.041

94. Cooper CL, Davis HL, Morris ML, Efler SM, Krieg AM, Li Y, et al. Safety and Immunogenicity of CPG 7909 Injection as an Adjuvant to Fluarix Influenza Vaccine. Vaccine (2004) 22:3136-43. doi: 10.1016/j.vaccine.2004.01.058

95. Lacey KA, Mulcahy ME, Towell AM, Geoghegan JA, McLoughlin RM. Clumping Factor B is an Important Virulence Factor During Staphylococcus aureus Skin Infection and a Promising Vaccine Target. PLoS Pathog (2019) 15. doi: 10.1371/journal.ppat.1007713

96. Lacey KA, Leech JM, Lalor SJ, McCormack N, Geoghegan JA, McLoughlin RM. The Staphylococcus aureus Cell Wall-Anchored Protein Clumping Factor a is an Important T Cell Antigen. Infect Immun (2017) 85. doi: 10.1128/IAI.00549-17

97. Date SV, Modrusan Z, Lawrence M, Morisaki JH, Toy K, Shah IM, et al. Global Gene Expression of Methicillin-Resistant Staphylococcus aureus USA300 During Human and Mouse Infection. J Infect Dis (2014) 209:1542-50. doi: 10.1093/infdis/jit668

98. Junhee Seok H, Shaw W, Alex GC, Michael NM, Henry VB, Xu W, et al. Genomic Responses in Mouse Models Poorly Mimic Human Inflammatory Diseases. Proc Natl Acad Sci USA (2013) 110:3507-12. doi: 10.1073/ pnas. 1222878110

99. Beura LK, Hamilton SE, Bi K, Schenkel JM, Odumade OA, Casey KA, et al. Normalizing the Environment Recapitulates Adult Human Immune Traits in Laboratory Mice. Nature (2016) 532:512-6. doi: 10.1038/nature17655

100. Tam K, Torres VJ. Staphylococcus aureus Secreted Toxins and Extracellular Enzymes. Microbiol Spectr (2019) 7. doi: 10.1128/microbiolspec.gpp3-0039-2018

101. Spaan AN, Van Strijp JAG, Torres VJ. Leukocidins: Staphylococcal BiComponent Pore-Forming Toxins Find Their Receptors. Nat Rev Microbiol (2017) 15:435-47. doi: 10.1038/nrmicro.2017.27

102. Tseng CW, Biancotti JC, Berg BL, Gate D, Kolar SL, Müller S, et al. Increased Susceptibility of Humanized NSG Mice to Panton-Valentine Leukocidin and Staphylococcus aureus Skin Infection. PLoS Pathog (2015) 11. doi: 10.1371/ journal.ppat.1005292

103. Knop J, Hanses F, Leist T, Archin NM, Buchholz S, Gläsner J, et al. Staphylococcus aureus Infection in Humanized Mice: A New Model to Study Pathogenicity Associated With Human Immune Response. J Infect Dis (2015) 212:435-44. doi: 10.1093/infdis/jiv073

104. Prince A, Wang H, Kitur K, Parker D. Humanized Mice Exhibit Increased Susceptibility to Staphylococcus aureus Pneumonia. J Infect Dis (2017) 215:1386-95. doi: 10.1093/infdis/jiw425

105. Parker D. Humanized Mouse Models of Staphylococcus aureus Infection. Front Immunol (2017) 8:512. doi: 10.3389/fimmu.2017.00512

106. Salgado-Pabón W, Schlievert PM. Models Matter: The Search for an Effective Staphylococcus aureus Vaccine. Nat Rev Microbiol (2014) 12:585-91. doi: 10.1038/nrmicro3308

107. Venkatasubramaniam A, Liao G, Cho E, Adhikari RP, Kort T, Holtsberg FW, et al. Safety and Immunogenicity of a 4-Component Toxoid-Based Staphylococcus aureus Vaccine in Rhesus Macaques. Front Immunol (2021) 12:621754. doi: 10.3389/fimmu.2021.621754

108. Verreault D, Ennis J, Whaley K, Killeen SZ, Karauzum H, Javad Aman M, et al. Effective Treatment of Staphylococcal Enterotoxin B Aerosol Intoxication in Rhesus Macaques by Using Two Parenterally Administered High-Affinity Monoclonal Antibodies. Antimicrob Agents Chemother (2019) 63. doi: 10.1128/AAC.02049-18

109. Schulz D, Grumann D, Trübe P, Pritchett-Corning K, Johnson S, Reppschläger K, et al. Laboratory Mice Are Frequently Colonized With Staphylococcus aureus and Mount a Systemic Immune Response-Note of Caution for In Vivo Infection Experiments. Front Cell Infect Microbiol (2017) 7:152. doi: 10.3389/fcimb.2017.00152

110. Holtfreter S, Radcliff FJ, Grumann D, Read H, Johnson S, Monecke S, et al. Characterization of a Mouse-Adapted Staphylococcus aureus Strain. PLoS One (2013) 8. doi: 10.1371/journal.pone.0071142
111. Flaxman A, Van Diemen PM, Yamaguchi Y, Allen E, Lindemann C, Rollier CS, et al. Development of Persistent Gastrointestinal S. aureus Carriage in Mice. Sci Rep (2017) 7. doi: 10.1038/s41598-017-12576-0

112. Leech JM, Dhariwala MO, Lowe MM, Chu K, Merana GR, Cornuot C, et al. Toxin-Triggered Interleukin-1 Receptor Signaling Enables Early-Life Discrimination of Pathogenic Versus Commensal Skin Bacteria. Cell Host Microbe (2019) 26:795-809.e5. doi: 10.1016/j.chom.2019.10.007

113. Lee B, Olaniyi R, Kwiecinski JM, Wardenburg JB. Staphylococcus aureus Toxin Suppresses Antigen-Specific T Cell Responses. J Clin Invest (2020) 130:1122-7. doi: 10.1172/JCI130728

114. Miller LG, Eells SJ, David MZ, Ortiz N, Taylor AR, Kumar N, et al. Staphylococcus aureus Skin Infection Recurrences Among Household Members: An Examination of Host, Behavioral, and Pathogen-Level Predictors. Clin Infect Dis (2015) 60:753-63. doi: 10.1093/cid/ciu943

115. Gomes MC, Mostowy S. The Case for Modeling Human Infection in Zebrafish. Trends Microbiol (2020) 28:10-8. doi: 10.1016/j.tim.2019.08.005

116. Hepburn L, Prajsnar TK, Klapholz C, Moreno P, Loynes CA, Ogryzko NV, et al. A Spaetzle-Like Role for Nerve Growth Factor $\beta$ in Vertebrate Immunity to Staphylococcus aureus. Science (2014) 346:641-6. doi: 10.1126/ science. 1258705

117. Mei F, Rolain M, Yi Zhou X, Kumar Singh P, Thummel R, Kumar A. Zebrafish Are Resistant to Staphylococcus aureus Endophthalmitis. Pathogens (2019) 8. doi: 10.3390/pathogens 8040207

118. Kim J, Koo BK, Knoblich JA. Human Organoids: Model Systems for Human Biology and Medicine. Nat Rev Mol Cell Biol (2020) 21:571-84. doi: 10.1038/ s41580-020-0259-3

119. Lee J, Rabbani CC, Gao H, Steinhart MR, Woodruff BM, Pflum ZE, et al. Hair-Bearing Human Skin Generated Entirely From Pluripotent Stem Cells. Nature (2020) 582:399-404. doi: 10.1038/s41586-020-2352-3

120. Nilsson Hall G, Mendes LF, Gklava C, Geris L, Luyten FP, Papantoniou I. Developmentally Engineered Callus Organoid Bioassemblies Exhibit Predictive In Vivo Long Bone Healing. Adv Sci (2020) 7. doi: 10.1002/ advs. 201902295

121. Leeman KT, Pessina P, Lee JH, Kim CF. Mesenchymal Stem Cells Increase Alveolar Differentiation in Lung Progenitor Organoid Cultures. Sci Rep (2019) 9. doi: 10.1038/s41598-019-42819-1

122. Dye BR, Hill DR, Ferguson MA, Tsai YH, Nagy MS, Dyal R, et al. In Vitro Generation of Human Pluripotent Stem Cell Derived Lung Organoids. Elife (2015) 2015:1-25. doi: 10.7554/eLife.05098

123. Clark RA, Chong B, Mirchandani N, Brinster NK, Yamanaka K, Dowgiert RK, et al. The Vast Majority of CLA + T Cells are Resident in Normal Skin. J Immunol (2006) 176:4431-9. doi: 10.4049/jimmunol.176.7.4431

124. Schoettler N, Hrusch CL, Blaine KM, Sperling AI, Ober C. Transcriptional Programming and T Cell Receptor Repertoires Distinguish Human Lung and Lymph Node Memory T Cells. Commun Biol (2019) 2. doi: 10.1038/ s42003-019-0657-2

125. Sun W, Luo Z, Lee J, Kim HJ, Lee KJ, Tebon P, et al. Organ-on-a-Chip for Cancer and Immune Organs Modeling. Adv Healthc Mater (2019) 8. doi: 10.1002/adhm.201801363

126. Kim JJ, Ellett F, Thomas CN, Jalali F, Anderson RR, Irimia D, et al. A Microscale, Full-Thickness, Human Skin on a Chip Assay Simulating Neutrophil Responses to Skin Infection and Antibiotic Treatments. Lab Chip (2019) 19:3094-103. doi: 10.1039/c9lc00399a

127. Deinhardt-Emmer S, Rennert K, Schicke E, Cseresnyés Z, Windolph M, Nietzsche S, et al. Co-Infection With Staphylococcus aureus After Primary Influenza Virus Infection Leads to Damage of the Endothelium in a Human Alveolus-on-a-Chip Model. Biofabrication (2020) 12. doi: 10.1088/17585090/ab7073

128. Santiago-Rodriguez TM, Naidu M, Jones MB, Ly M, Pride DT. Identification of Staphylococcal Phage With Reduced Transcription in Human Blood Through Transcriptome Sequencing. Front Microbiol (2015) 6:216. doi: $10.3389 /$ fmicb. 2015.00216

129. Ibberson CB, Whiteley M. The Staphylococcus aureus Transcriptome During Cystic Fibrosis Lung Infection. MBio (2019) 10. doi: 10.1128/ mBio.02774-19

130. Boero E, Mnich ME, Manetti AGO, Soldaini E, Grimaldi L, Bagnoli F. Human Three-Dimensional Models for Studying Skin Pathogens. Curr Topics Microbiol Immunol (2020) 430:3-27. doi: 10.1007/82_2020_219 
131. Mandal A, Boopathy AV, Lam LKW, Moynihan KD, Welch ME, Bennett NR, et al. Cell and Fluid Sampling Microneedle Patches for Monitoring SkinResident Immunity. Sci Transl Med (2018) 10. doi: 10.1126/scitranslmed. aar2227

132. Olaniyi RO, Pancotto L, Grimaldi L, Bagnoli F. Deciphering the Pathological Role of Staphylococcal $\alpha$-Toxin and Panton-Valentine Leukocidin Using a Novel Ex Vivo Human Skin Model. Front Immunol (2018) 9:951. doi: 10.3389/fimmu.2018.00951

133. Steinstraesser L, Sorkin M, Niederbichler AD, Becerikli M, Stupka J, Daigeler A, et al. A Novel Human Skin Chamber Model to Study Wound Infection Ex Vivo. Arch Dermatol Res (2010) 302:357-65. doi: 10.1007/s00403-009-1009-8

134. Hendriks A, Mnich ME, Clemente B, Cruz AR, Tavarini S, Bagnoli F, et al. Staphylococcus aureus-Specific Tissue-Resident Memory CD4+ T Cells are Abundant in Healthy Human Skin. Front Immunol (2021) 12:642711. doi: 10.3389/fimmu.2021.642711

135. Clegg J, Soldaini E, Bagnoli F, McLoughlin RM. Targeting Skin-Resident Memory T Cells via Vaccination to Combat Staphylococcus aureus Infections. Trends Immunol (2021) 42:6-17. doi: 10.1016/j.it.2020.11.005

136. Yeaman MR, Filler SG, Chaili S, Barr K, Wang H, Kupferwasser D, et al. Mechanisms of NDV-3 Vaccine Efficacy in MRSA Skin Versus Invasive Infection. Proc Natl Acad Sci USA (2014) 111:E5555-63. doi: 10.1073/pnas.1415610111

137. Schmidt CS, White CJ, Ibrahim AS, Filler SG, Fu Y, Yeaman MR, et al. NDV-3, a Recombinant Alum-Adjuvanted Vaccine for Candida and Staphylococcus aureus, Is Safe and Immunogenic in Healthy Adults. Vaccine (2012) 30:7594-600. doi: 10.1016/j.vaccine.2012.10.038

138. Zeng H, Yang F, Feng Q, Zhang J, Gu J, Jing H, et al. Rapid and Broad Immune Efficacy of a Recombinant Five-Antigen Vaccine Against Staphylococcus aureus Infection in Animal Models. Vaccines (2020) 8. doi: $10.3390 /$ vaccines 8010134

139. Inoue M, Yonemura T, Baber J, Shoji Y, Aizawa M, Cooper D, et al. Safety, Tolerability, and Immunogenicity of a Novel 4-Antigen Staphylococcus aureus Vaccine (SA4Ag) in Healthy Japanese Adults. Hum Vaccines Immunother (2018) 14:2682-91. doi: 10.1080/21645515.2018.1496764

140. Creech CB, Frenck RW, Sheldon EA, Seiden DJ, Kankam MK, Zito ET, et al. Safety, Tolerability, and Immunogenicity of a Single Dose 4-Antigen or 3-Antigen Staphylococcus aureus Vaccine in Healthy Older Adults: Results of a Randomised Trial. Vaccine (2017) 35:385-94. doi: 10.1016/j.vaccine.2016.11.032

141. Frenck RW, Buddy Creech C, Sheldon EA, Seiden DJ, Kankam MK, Baber J, et al. Safety, Tolerability, and Immunogenicity of a 4-Antigen Staphylococcus aureus Vaccine (SA4Ag): Results From a First-in-Human Randomised, Placebo-Controlled Phase 1/2 Study. Vaccine (2017) 35:37584. doi: 10.1016/j.vaccine.2016.11.010

142. Karauzum H, Venkatasubramaniam A, Adhikari RP, Kort T, Holtsberg FW, Mukherjee I, et al. IBT-V02: A Multicomponent Toxoid Vaccine Protects Against Primary and Secondary Skin Infections Caused by Staphylococcus aureus. Front Immunol (2021) 12. doi: 10.3389/fimmu.2021.624310

143. Miller LS, Fowler VG, Shukla SK, Rose WE, Proctor RA. Development of a Vaccine Against Staphylococcus aureus Invasive Infections: Evidence Based on Human Immunity, Genetics and Bacterial Evasion Mechanisms. FEMS Microbiol Rev (2019) 44:123-53. doi: 10.1093/femsre/fuz030

144. Spellberg B, Ibrahim AS, Yeaman MR, Lin L, Fu Y, Avanesian V, et al. The Antifungal Vaccine Derived From the Recombinant N Terminus of Als3p Protects Mice Against the Bacterium Staphylococcus aureus. Infect Immun (2008) 76:4574-80. doi: 10.1128/IAI.00700-08

145. Nagasawa Y, Kiku Y, Sugawara K, Hirose A, Kai C, Kitano N, et al. Staphylococcus aureus-Specific Iga Antibody in Milk Suppresses the Multiplication of S. aureus in Infected Bovine Udder. BMC Vet Res (2019) 15. doi: 10.1186/s12917-019-2025-3

146. Kim MW, Greenfield BK, Snyder RE, Steinmaus CM, Riley LW. The Association Between Community-Associated Staphylococcus aureus Colonization and Disease: A Meta-Analysis. BMC Infect Dis (2018) 18. doi: 10.1186/s12879-018-2990-3

147. Wertheim HFL, Vos MC, Ott A, Van Belkum A, Voss A, Kluytmans JAJW, et al. Risk and Outcome of Nosocomial Staphylococcus aureus Bacteraemia in Nasal Carriers Versus Non-Carriers. Lancet (2004) 364:703-5. doi: 10.1016/S0140-6736(04)16897-9

148. Goodyear CS, Sugiyama F, Silverman GJ. Temporal and Dose-Dependent Relationships Between In Vivo B Cell Receptor-Targeted Proliferation and
Deletion-Induced by a Microbial B Cell Toxin. J Immunol (2006) 176:226271. doi: 10.4049/jimmunol.176.4.2262

149. Nygaard TK, Pallister KB, DuMont AL, DeWald M, Watkins RL, Pallister EQ, et al. Alpha-Toxin Induces Programmed Cell Death of Human T Cells, B Cells, and Monocytes During USA300 Infection. PLoS One (2012) 7. doi: 10.1371/journal.pone. 0036532

150. Becker KA, Fahsel B, Kemper H, Mayeres J, Li C, Wilker B, et al. Staphylococcus aureus Alpha-Toxin Disrupts Endothelial-Cell Tight Junctions via Acid Sphingomyelinase and Ceramide. Infect Immun (2018) 86. doi: 10.1128/IAI.00606-17

151. Surewaard BGJ, Thanabalasuriar A, Zeng Z, Tkaczyk C, Cohen TS, Bardoel $B W$, et al. $\alpha$-Toxin Induces Platelet Aggregation and Liver Injury During Staphylococcus aureus Sepsis. Cell Host Microbe (2018) 24:271-284.e3. doi: 10.1016/j.chom.2018.06.017

152. Shenoy AT, Wasserman GA, Arafa EI, Wooten AK, Smith NMS, Martin IMC, et al. Lung CD4+ Resident Memory T Cells Remodel Epithelial Responses to Accelerate Neutrophil Recruitment During Pneumonia. Mucosal Immunol (2020) 13:334-43. doi: 10.1038/s41385-019-0229-2

153. Jansson B, Uhlén M, Nygren PÅ. All Individual Domains of Staphylococcal Protein a Show Fab Binding. FEMS Immunol Med Microbiol (1998) 20:6978. doi: 10.1016/S0928-8244(97)00108-9

154. Graille M, Stura EA, Corper AL, Sutton BJ, Taussig MJ, Charbonnier JB, et al. Crystal Structure of a Staphylococcus aureus Protein a Domain Complexed With the Fab Fragment of a Human Igm Antibody: Structural Basis for Recognition of B-Cell Receptors and Superantigen Activity. Proc Natl Acad Sci USA (2000) 97:5399-404. doi: 10.1073/pnas.97.10.5399

155. William T Lee DKJ. Staphylococcal Enterotoxin B (SEB) Induces Memory CD4 T Cell Anergy In Vivo and Impairs Recall Immunity to Unrelated Antigens. J Clin Cell Immunol (2015) 06:1-8. doi: 10.4172/2155-9899.1000346

156. Nishitani K, Beck CA, Rosenberg AF, Kates SL, Schwarz EM, Daiss JL. A Diagnostic Serum Antibody Test for Patients With Staphylococcus aureus Osteomyelitis. Clin Orthop Relat Res (2015) 473:2735-49. doi: 10.1007/ s11999-015-4354-2

157. Aman MJ. Integrated Biotherapeutics. Hum Vaccines Immunother (2018) 14:1308-10. doi: 10.1080/21645515.2018.1440105

158. Chen WH, Pasetti MF, Adhikari RP, Baughman H, Douglas R, El-Khorazaty J, et al. Safety and Immunogenicity of a Parenterally Administered, Structure-Based Rationally Modified Recombinant Staphylococcal Enterotoxin B Protein Vaccine, Stebvax. Clin Vaccine Immunol (2016) 23:918-25. doi: 10.1128/CVI.00399-16

159. Wang FD, Chen YY, Chen TL, Liu CY. Risk Factors and Mortality in Patients With Nosocomial Staphylococcus aureus Bacteremia. Am J Infect Control (2008) 36:118-22. doi: 10.1016/j.ajic.2007.02.005

160. Liu C, Bayer A, Cosgrove SE, Daum RS, Fridkin SK, Gorwitz RJ, et al. Clinical Practice Guidelines by the Infectious Diseases Society of America for the Treatment of Methicillin-Resistant Staphylococcus aureus Infections in Adults and Children. Clin Infect Dis (2011) 52. doi: 10.1093/cid/ciq146

161. World Health Organization. 2019 Antibacterial Agents in Clinical Development: An Analysis of the Antibacterial Clinical Development Pipeline. Geneva: World Health Organization (2019).

162. Organization WH. Antibacterial Agents in Preclinical Development: An Open Access Database. World Health Organization (2019) p. 20.

163. Zhou C, Cai H, Baruch A, Lewin-Koh N, Yang M, Guo F, et al. Sustained Activity of Novel THIOMAB Antibody-Antibiotic Conjugate Against Staphylococcus aureus in a Mouse Model: Longitudinal Pharmacodynamic Assessment by Bioluminescence Imaging. PLoS One (2019) 14. doi: 10.1371/ journal.pone.0224096

164. Lehar SM, Pillow T, Xu M, Staben L, Kajihara KK, Vandlen R, et al. Novel Antibody-Antibiotic Conjugate Eliminates Intracellular S. aureus. Nature (2015) 527:323-8. doi: 10.1038/nature16057

165. Peck M, Rothenberg ME, Deng R, Lewin-Koh N, She G, Kamath AV, et al. A Phase 1, Randomized, Single-Ascending-Dose Study to Investigate the Safety, Tolerability, and Pharmacokinetics of DSTA4637S, an AntiStaphylococcus aureus Thiomab Antibody-Antibiotic Conjugate, in Healthy Volunteers. Antimicrob Agents Chemother (2019) 63. doi: 10.1128/ AAC.02588-18

166. Geriak M, Haddad F, Rizvi K, Rose W, Kullar R, LaPlante K, et al. Clinical Data on Daptomycin Plus Ceftaroline Versus Standard of Care Monotherapy 
in the Treatment of Methicillin-Resistant Staphylococcus aureus Bacteremia. Antimicrob Agents Chemother (2019) 63. doi: 10.1128/AAC.02483-18

167. Sakoulas G, Okumura CY, Thienphrapa W, Olson J, Nonejuie P, Dam Q, et al. Nafcillin Enhances Innate Immune-Mediated Killing of MethicillinResistant Staphylococcus aureus. J Mol Med (2014) 92:139-49. doi: 10.1007/ s00109-013-1100-7

168. Mezey É, Nemeth K. Mesenchymal Stem Cells and Infectious Diseases: Smarter Than Drugs. Immunol Lett (2015) 168:208-14. doi: 10.1016/ j.imlet.2015.05.020

169. Yuan Y, lin S, Guo N, Zhao C, Shen S, Bu X, et al. Marrow Mesenchymal Stromal Cells Reduce Methicillin-Resistant Staphylococcus aureus Infection in Rat Models. Cytotherapy (2014) 16:56-63. doi: 10.1016/j.jcyt.2013.06.002

170. Yoshitani J, Kabata T, Arakawa H, Kato Y, Nojima T, Hayashi K, et al. Combinational Therapy With Antibiotics and Antibiotic-Loaded AdiposeDerived Stem Cells Reduce Abscess Formation in Implant-Related Infection in Rats. Sci Rep (2020) 10. doi: 10.1038/s41598-020-68184-y

171. Johnson CT, Sok MCP, Martin KE, Kalelkar PP, Caplin JD, Botchwey EA, et al. Lysostaphin and BMP-2 Co-Delivery Reduces S. aureus Infection and Regenerates Critical-Sized Segmental Bone Defects. Sci Adv (2019) 5. doi: 10.1126/sciadv.aaw1228

172. Hussain S, Joo J, Kang J, Kim B, Braun GB, She ZG, et al. Antibiotic-Loaded Nanoparticles Targeted to the Site of Infection Enhance Antibacterial Efficacy. Nat BioMed Eng (2018) 2:95-103. doi: 10.1038/s41551-017-0187-5

173. Lara HH, Lopez-Ribot JL. Inhibition of Mixed Biofilms of Candida Albicans and Methicillin-Resistant Staphylococcus aureus by Positively Charged Silver Nanoparticles and Functionalized Silicone Elastomers. Pathogens (2020) 9:1-14. doi: 10.3390/pathogens9100784

174. Kong EF, Tsui C, Kucharíková S, Andes D, Van Dijck P, Jabra-Rizk MA. Commensal Protection of Staphylococcus aureus Against Antimicrobials by Candida Albicans Biofilm Matrix. MBio (2016) 7. doi: 10.1128/mBio.01365-16

175. Watts G. Phage Therapy: Revival of the Bygone Antimicrobial. Lancet (Lond Engl) (2017) 390:2539-40. doi: 10.1016/S0140-6736(17)33249-X

176. Jun SY, Jung GM, Yoon SJ, Oh MD, Choi YJ, Lee WJ, et al. Antibacterial Properties of a Pre-Formulated Recombinant Phage Endolysin, SAL-1. Int J Antimicrob Agents (2013) 41:156-61. doi: 10.1016/j.ijantimicag.2012.10.011

177. Kim NH, Park WB, Cho JE, Choi YJ, Choi SJ, Jun SY, et al. Effects of Phage Endolysin SAL200 Combined With Antibiotics on Staphylococcus aureus Infection. Antimicrob Agents Chemother (2018) 62. doi: 10.1128/AAC.00731-18

178. Jun SY, Jang IJ, Yoon S, Jang K, Yu KS, Cho JY, et al. Pharmacokinetics and Tolerance of the Phage Endolysin-Based Candidate Drug SAL200 After a Single Intravenous Administration Among Healthy Volunteers. Antimicrob Agents Chemother (2017) 61. doi: 10.1128/AAC.02629-16

179. Fowler VG, Das AF, Lipka-Diamond J, Schuch R, Pomerantz R, JáureguiPeredo L, et al. Exebacase for Patients With Staphylococcus aureus Bloodstream Infection and Endocarditis. J Clin Invest (2020) 130:3750-60. doi: $10.1172 /$ JCI136577

180. Ooi ML, Drilling AJ, Morales S, Fong S, Moraitis S, MacIas-Valle L, et al. Safety and Tolerability of Bacteriophage Therapy for Chronic Rhinosinusitis Due to Staphylococcus aureus. JAMA Otolaryngol - Head Neck Surg (2019) 145:723-9. doi: 10.1001/jamaoto.2019.1191

181. Petrovic Fabijan A, Lin RCY, Ho J, Maddocks S, Ben Zakour NL, Iredell JR, et al. Safety of Bacteriophage Therapy in Severe Staphylococcus aureus Infection. Nat Microbiol (2020) 5:465-72. doi: 10.1038/s41564-019-0634-Z

182. Kolenda C, Josse J, Medina M, Fevre C, Lustig S, Ferry T, et al. Evaluation of the Activity of a Combination of Three Bacteriophages Alone or in Association With Antibiotics on Staphylococcus aureus Embedded in Biofilm or Internalized in Osteoblasts. Antimicrob Agents Chemother (2020) 64. doi: 10.1128/AAC.02231-19

183. DeJonge M, Burchfield D, Bloom B, Duenas M, Walker W, Polak M, et al. Clinical Trial of Safety and Efficacy of IHN-A21 for the Prevention of Nosocomial Staphylococcal Bloodstream Infection in Premature Infants. J Pediatr (2007) 151:260-265. doi: 10.1016/j.jpeds.2007.04.060

184. Patel M, Kaufman DA. Anti-Lipoteichoic Acid Monoclonal Antibody (Pagibaximab) Studies for the Prevention of Staphylococcal Bloodstream Infections in Preterm Infants. Expert Opin Biol Ther (2015) 15:595-600. doi: 10.1517/14712598.2015.1019857

185. Rupp ME, Holley HP, Lutz J, Dicpinigaitis PV, Woods CW, Levine DP, et al. Randomized, Multicenter, Double-Blind, Placebo-Controlled Trial of a
Polyclonal Anti-Staphylococcus aureus Capsular Polysaccharide Immune Globulin in Treatment of Staphylococcus aureus Bacteremia. Antimicrob Agents Chemother (2007) 51:4249-54. doi: 10.1128/AAC.00570-07

186. Stryjewski ME, Lentnek A, O'Riordan W, Pullman J, Tambyah PA, Miró JM, et al. A Randomized Phase 2 Trial of Telavancin Versus Standard Therapy in Patients With Uncomplicated Staphylococcus aureus Bacteremia: The ASSURE Study. BMC Infect Dis (2014) 14. doi: 10.1186/1471-2334-14-289

187. Magyarics Z, Leslie F, Bartko J, Rouha H, Luperchio S, Schörgenhofer C, et al. Randomized, Double-Blind, Placebo-Controlled, Single-Ascending-Dose Study of the Penetration of a Monoclonal Antibody Combination (ASN100) Targeting Staphylococcus aureus Cytotoxins in the Lung Epithelial Lining Fluid of Healthy Volunteers. Antimicrob Agents Chemother (2019) 63. doi: 10.1128/AAC.00350-19

188. François B, Mercier E, Gonzalez C, Asehnoune K, Nseir S, Fiancette M, et al. Safety and Tolerability of a Single Administration of AR-301, a Human Monoclonal Antibody, in ICU Patients With Severe Pneumonia Caused by Staphylococcus aureus: First-in-Human Trial. Intensive Care Med (2018) 44:1787-96. doi: 10.1007/s00134-018-5229-2

189. François B, Garcia Sanchez M, Eggimann P, Dequin P-F, Laterre P-F, Huberlant V, et al. Efficacy and Safety Profile of Suvratoxumab, a Novel Anti-Staphylococcus aureus Monoclonal Antibody: Results of the SAATELLITE Study in Mechanically Ventilated Intensive Care Unit Patients. 29th Eur Congr Clin Microbiol Infect Dis Amsterdam (2019).

190. Huynh T, Stecher M, Mckinnon J, Jung N, Rupp ME. Safety and Tolerability of 514G3, a True Human Anti-Protein a Monoclonal Antibody for the Treatment of S. aureus Bacteremia. Open Forum Infect Dis (2016) 3. doi: 10.1093/ofid/ofw172.1057

191. Tkaczyk C, Semenova E, Shi YY, Rosenthal K, Oganesyan V, Warrener P, et al. Alanine Scanning Mutagenesis of the MEDI4893 (Suvratoxumab) Epitope Reduces Alpha Toxin Lytic Activity In Vitro and Staphylococcus aureus Fitness in Infection Models. Antimicrob Agents Chemother (2018) 62. doi: 10.1128/AAC.01033-18

192. Yu XQ, Robbie GJ, Wu Y, Esser MT, Jensen K, Schwartz HI, et al. Safety, Tolerability, and Pharmacokinetics of MEDI4893, an Investigational, Extended-Half-Life, Anti-Staphylococcus aureus Alpha-Toxin Human Monoclonal Antibody, in Healthy Adults. Antimicrob Agents Chemother (2017) 61. doi: 10.1128/AAC.01020-16

193. Rouha H, Badarau A, Visram ZC, Battles MB, Prinz B, Magyarics Z, et al. Five Birds, One Stone: Neutralization of $\alpha$-Hemolysin and 4 Bi-Component Leukocidins of Staphylococcus aureus With a Single Human Monoclonal Antibody. MAbs (2015) 7:243-54. doi: 10.4161/19420862.2014.985132

194. Rouha H, Weber S, Janesch P, Maierhofer B, Gross K, Dolezilkova I, et al. Disarming Staphylococcus aureus From Destroying Human Cells by Simultaneously Neutralizing Six Cytotoxins With Two Human Monoclonal Antibodies. Virulence (2018) 9:231-47. doi: 10.1080/ 21505594.2017.1391447

195. Diep BA, Le VTM, Visram ZC, Rouha H, Stulik L, Dip EC, et al. Improved Protection in a Rabbit Model of Community-Associated MethicillinResistant Staphylococcus aureus Necrotizing Pneumonia Upon Neutralization of Leukocidins in Addition to Alpha-Hemolysin. Antimicrob Agents Chemother (2016) 60:6333-40. doi: 10.1128/ AAC.01213-16

196. Van Loghem E, Frangione B, Recht B, Franklin EC. Staphylococcal Protein a and Human Igg Subclasses and Allotypes. Scand J Immunol (1982) 15:275-8. doi: 10.1111/j.1365-3083.1982.tb00649.x

197. Varshney AK, Kuzmicheva GA, Lin JB, Sunley KM, Bowling RA, Kwan TY, et al. A Natural Human Monoclonal Antibody Targeting Staphylococcus Protein a Protects Against Staphylococcus aureus Bacteremia. PLoS One (2018) 13. doi: 10.1371/journal.pone.0190537

198. Pelegrin M, Naranjo-Gomez M, Piechaczyk M. Antiviral Monoclonal Antibodies: Can They be More Than Simple Neutralizing Agents? Trends Microbiol (2015) 23:653-65. doi: 10.1016/j.tim.2015.07.005

199. Diem MD, Hyun L, Yi F, Hippensteel R, Kuhar E, Lowenstein C, et al. Selection of High-Affinity Centyrin FN3 Domains From a Simple Library Diversified at a Combination of Strand and Loop Positions. Protein Eng Des Sel (2014) 27:419-29. doi: 10.1093/protein/gzu016

200. Jacobs SA, Diem MD, Luo J, Teplyakov A, Obmolova G, Malia T, et al. Design of Novel FN3 Domains With High Stability by a Consensus Sequence 
Approach. Protein Eng Des Sel (2012) 25:107-17. doi: 10.1093/protein/ gzr064

201. Chan R, Buckley PT, O’Malley A, Sause WE, Alonzo F, Lubkin A, et al. Identification of Biologic Agents to Neutralize the Bicomponent Leukocidins of Staphylococcus aureus. Sci Transl Med (2019) 11. doi: 10.1126/ scitranslmed.aat 0882

202. Jacobs SA, Gibbs AC, Conk M, Yi F, Maguire D, Kane C, et al. Fusion to a Highly Stable Consensus Albumin Binding Domain Allows for Tunable Pharmacokinetics. Protein Eng Des Sel (2015) 28:385-93. doi: 10.1093/ protein/gzv040

203. Bistoni F, Vecchiarelli A, Cenci E, Puccetti P, Marconi P, Cassone A. Evidence for Macrophage-Mediated Protection Against Lethal Candida Albicans Infection. Infect Immun (1986) 51:668-74. doi: 10.1128/ iai.51.2.668-674.1986

204. Ciarlo E, Heinonen T, Théroude C, Asgari F, Le Roy D, Netea MG, et al. Trained Immunity Confers Broad-Spectrum Protection Against Bacterial Infections. J Infect Dis (2020) 222:1869-81. doi: 10.1093/infdis/jiz692

205. Garly ML, Martins CL, Balé C, Baldé MA, Hedegaard KL, Gustafson P, et al. BCG Scar and Positive Tuberculin Reaction Associated With Reduced Child
Mortality in West Africa: A non-Specific Beneficial Effect of BCG? Vaccine (2003) 21:2782-90. doi: 10.1016/S0264-410X(03)00181-6

Conflict of Interest: JC is a $\mathrm{PhD}$ fellow who is enrolled in the School of Biochemistry and Immunology at Trinity College Dublin and participates in a postgraduate studentship program at GSK. ES, SR, FB, and SP are employees of the GSK group of companies.

The remaining author declares that the research was conducted in the absence of any commercial or financial relationships that could be construed as a potential conflict of interest.

Copyright (c) 2021 Clegg, Soldaini, McLoughlin, Rittenhouse, Bagnoli and Phogat. This is an open-access article distributed under the terms of the Creative Commons Attribution License (CC BY). The use, distribution or reproduction in other forums is permitted, provided the original author(s) and the copyright owner(s) are credited and that the original publication in this journal is cited, in accordance with accepted academic practice. No use, distribution or reproduction is permitted which does not comply with these terms. 